\title{
Economic Retirement Age and Lifelong Learning
}

- a theoretical model with heterogeneous labor, biased technical change and international sourcing

\author{
Thomas Gries \\ Stefan Jungblut \\ Tim Krieger \\ Henning Meyer
}

\section{CESIFO WORKING PAPER NO. 6257}

CATEGORY 4: LABOUR MARKETS

DECEMBER 2016

An electronic version of the paper may be downloaded

- from the SSRN website:

- from the RePEc website:

- from the CESifo website:

www.SSRN.com

Www.RePEc.org

www.CESifo-group.org/wp 


\title{
Economic Retirement Age and Lifelong Learning
}

- a theoretical model with heterogeneous labor, biased technical change and international sourcing

\begin{abstract}
The employability of an aging population in a world of continuous and biased technical change is top of the political agenda. Due to endogenous human capital depreciation the effective retirement age is often below statutory retirement age resulting in permanent non-employability of older workers. We analyze this phenomenon in a putty-putty human capital vintage model and focus on education and the speed of human capital depreciation. Introducing a two-stage education system with initial schooling and lifelong learning, not even lifelong learning turns out to be capable of aligning economic and statutory retirement. However, well designed education programs will keep more workers in highly productive activities at the end of their working life, and hence will substitute for simple social transfers, or for an early switch towards very low paid jobs.
\end{abstract}

JEL-Codes: J260, O330, J640.

Keywords: lifelong learning, retirement, employability, education system, heterogeneous labor, biased technical change.

\author{
Thomas Gries* \\ Paderborn University \\ Warburgerstrasse 100 \\ Paderborn / Germany \\ thomas.gries@notes.upb.de \\ Tim Krieger \\ University of Freiburg \\ Wilhelmstr. $1 b$ \\ Freiburg i.Br. / Germany \\ tim.krieger@vwl.uni-freiburg.de
}

Stefan Jungblut

Paderborn University

Warburgerstrasse 100

Paderborn / Germany

stefan.jungblut@upb.de

Henning Meyer

Paderborn University

Warburgerstrasse 100

Paderborn / Germany

henning7.meyer@volkswagen.de

*corresponding author

December 8, 2016

We are very grateful for the detailed comments of two anonymous reviewers which helped us to substantially improve the quality of this contribution. 


\section{Introduction}

In many OECD countries, the effective retirement age is well below the statutory retirement age. The main reason for the low labor-force participation of the 55 to 64 age group is high net withdrawal rates, i.e., a major reduction in employment figures when moving to the next higher age group. At the same time, many governments consider extending working life the dominant strategy for keeping the pension system sustainable, ${ }^{1}$ while keeping the standard of living (almost) constant as individuals continue to earn an income. This argument, however, depends strongly on the supply of and demand for older workers. It implicitly presumes that workers remain employable until the new, higher retirement age. However, if the effective, or rather economic, retirement age does not increase when the government raises the statutory retirement age, for large groups old-age poverty due to non-employment could be the result.

For instance, Butrica et al. (2002) show that raising the statutory retirement age will contribute strongly to the projected rise in old-age poverty in the US. ${ }^{2}$ Likewise, several authors see extended periods of non-employment as a major explanation for old-age poverty (see, e.g., Smeeding, 1999, 2001; Gottschalk, 2006; or Favreault and Steuerle, 2008). More specifically, there are several pathways to non-employment of older workers (Riphahn, 1997), which may cause reductions in income due to low replacement rates. Later, this will result in lower pension benefits. Individuals, especially those with low human capital, tend to end up either on disability insurance, unemployment insurance, or the early retirement schemes, ${ }^{3}$ implying that pension reforms cause spillover effects in several directions and branches of the welfare system. Yet another potential consequence is that some workers are forced to enter a "no-skill service sector" where simple tasks are done for very low wages (e.g., household cleaning, security services).

Against this background, protecting the employability of older people is a highly important issue in the context of any pension reform that involves raising the statutory retirement age. As Holzmann (2005) argues the employability of older workers calls for changes in these workers' wage profiles and for measures to maintain and raise their productivity, especially through lifelong learning. To this day, however, the majority of older workers appears to be kept from working until the age of 67 and

\footnotetext{
${ }^{1}$ See e.g., Barr (2004, p. 209) or Cremer and Pestieau (2003) who even expect a "double dividend" from raising the statutory retirement age. Based on an OLG-CGE model, Marchiori (2008) explicitly considers raising the retirement age for unskilled workers in Europe to be the most effective measure for relieving fiscal pressure.

${ }^{2}$ Considering above-NAIRU economies, Michello and Ford (2006) argue that increasing retirement age will directly add to unemployment.

${ }^{3}$ There is no doubt that a pension system's fiscal impact plays an important role in keeping labor-force participation of older workers low, for example by early-retirement schemes (see e.g., Gruber and Wise, 1999; or Fenge and Pestieau, 2006). However, according to Duval (2003) only about one third of the decline in older males' labor-force participation rate can be attributed to implicit tax rates and retirement age. Johnson's (2000) estimate of this measure is even lower at 11 per cent.
} 
beyond, as there is insufficient demand for this type of labor. Standard arguments are costly seniority rules (Lazear, 1979, 1981) and youth unemployment, which is hoped to be overcome by pushing older workers out of work (see the discussion in Boldrin et al., 1999). Fenge and Pestieau (2006, p. 107) point out four potential explanations for the (forced) labour-market exit of older workers:

- Low-skilled older workers may exhibit declining relative productivity in times of rapid technological change.

- Insufficient training may contribute to declining productivity among older workers.

- Rigid age-earnings profiles caused by specific institutional arrangements (e.g. employment-protection legislation) reduce employment opportunities for the older unemployed.

- Temporary negative demand shocks may lead to an irreversible labor force withdrawal.

In the present paper, we examine the employability of an ageing population in a world of continuous technical change, leading to ever-new demands on the current labor force, who may or may not adapt to these though education and learning. Therefore, we focus on the first two propositions by Fenge and Pestieau (2006) which emphasize the effects of workers' abilities on labor demand. ${ }^{4}$ Let us be more specific about this in the following.

Our starting point is the observation that in today's fast-changing knowledge economies, people need to continue upgrading their skills throughout their adult lives - in both the personal and professional domain - to cope with modern life (OECD, 2007). Only this guarantees that they will remain employable for the duration of their working life and beyond. In fact, several studies observe a growing importance of certain general and cognitive skills in the labor market. ${ }^{5}$ Not surprisingly, lifelong learning for all has become a widely shared policy objective among industrialized countries. A striking example is the European Union (starting with the Lisbon Strategy) which concluded that a "need for a continuous renewal of citizens' knowledge, skills and competencies is crucial for the EU's competitiveness and social cohesion" (EU Commission, 2006). Therefore, one central focus of our model will be whether investing into general education or lifelong learning, respectively, will indeed help to synchronize the economic and the statutory retirement age.

Over the past thirty years, in almost all industrialized countries the demand for labor has shifted in favor of skilled workers. There is substantial evidence that skillbiased technological progress and the globalization of production are among the main driving forces of this shift in demand. ${ }^{6}$ As already mentioned in the OECD

\footnotetext{
${ }^{4}$ The other two propositions are exogenous variations (government policy, global demand shifts) unrelated to workers' abilities.

${ }^{5}$ See e.g., Gould (2002), Weinberg (2000), Murname et al. (1995) or Taber (2001). According to Bishop (1991), however, the results are not as clear-cut.

${ }^{6}$ See Chennells and van Reenen (2002) or recently Acemoglu and Autor (2011) for a broad discussion of literature on skill biased technological progress, OECD (1997) or more recently Harrison and McMillan (2011) for employment effects of internationalisation, and Nickell and Bell (1996) for the impact on unemployment.
} 
Jobs Strategy (OECD, 1994), many industrialized countries have responded by taking measures to improve the education of the workforce in order to avoid (relative) skill depreciation, which occurs when workers' skills stagnate while technology advances. ${ }^{7}$ Since technologically induced skill depreciation affects in particular older workers, ${ }^{8}$ adult training and lifelong learning are essential parts of these programs. As the OECD (2004) finds, "for older and low-educated workers, training allows attaining and maintaining the competencies required to bring productivity in line with market wages, thereby sustaining employment prospects of these groups" (OECD, 2004, p. 185). Specifically, these competencies should be sufficiently general to facilitate adjustment to technological change (Welch, 1970) and/or to future shocks as only this reduces uncertainty such that lower human capital investment is avoided (Lehvari and Weiss, 1974).

We use these considerations as the point of departure for our model. We focus on the production process and analyze the depreciation of human capital of a heterogeneous and aging workforce. We obtain conditions for the economic retirement age of this workforce. While all workers enjoy access to the same education, namely initial schooling and thereafter a lifelong learning program, the distribution of learning capabilities affects workers in different ways. For a given level of spending on a lifelong learning program, a fraction of the workforce becomes adaptable to new generations of technologies. For the remaining workers the present lifelong learning program is not successful. They are left with vintage-specific skills acquired during initial schooling. These skills, however, are subject to economic depreciation as the generations of technologies age. We choose a vintage model because technological change affects existing and new production processes asymmetrically. To avoid results that are simply due to a limitational production structure, the vintage model is of the putty-putty type. In a putty-putty vintage model, production factors can be substituted at the time when the technology is installed and when it is in use.

Our analysis will show that technological progress leads to a specific employment structure. Due to technological progress, the most recent vintages of adaptable workers are most productive. Therefore, the demand and the input of adaptable workers decline as vintages age. Accordingly, due to cross effects of production factors the productivity of vintage-specific skills in older vintages decreases as well. The depreciation of vintage-specific human capital endogenously determines the economic retirement age of the respective workers. If economic retirement age falls short of statutory retirement age, non-employment at old age results. Even fully flexible wages will not be able to generate a market equilibrium in the labor market segment of older workers. While labor with adaptable technological skills is able to switch to any technology efficiently, workers offering vintage-specific skills are discarded no matter what wage they would agree to work for.

Although technological progress is most important for the human capital depreciation process, it is also the most difficult to influence. Improving education is often suggested as a way to increase the productivity of aging labor and thus to keep

\footnotetext{
${ }^{7}$ See e.g. OECD (1994) for an analysis and OECD (2003) for related policy recommendations.

${ }^{8}$ See OECD (2004), Ch. 4 and the references therein.
} 
workers employed until they reach statutory retirement age. However, while this appears plausible at a first glance, it is not the outcome of our theoretical analysis. We distinguish between two stages of education, initial schooling and lifelong learning with all workers having to undergo both stages of education. Depending on their educational success, they will obtain adaptable or vintage-specific skills. With respect to the effects of education policy, we find that:

Education, no matter whether through initial schooling or lifelong learning programs, cannot synchronize the effective, economic and statutory retirement for workers with lower learning capabilities (vintage skills). However, labor market conditions for aging workers improve if a lifelong learning program is added to initial schooling. Well designed education programs combining these two elements will lead to a smaller fraction of labor that has to leave highly productive activities in the technology using sector at the end of their working life. In a model variation with a no-skill service sector well designed education efforts will improve conditions, even if this low-wage sector does not need any skills. There are two positive effects. First, vintages switch to the low payment service sector later, and second, wages in the no-skill service sector increase. Hence, well designed education policies can substitute for simple social transfers or wage subsidies for too low paid jobs.

To the best of our knowledge, our model is the first to analyze retirement behavior, lifelong learning and interactions with the welfare state using a model of vintagespecific human capital. With this, we contribute to the broader literature on technology adoption and the role of education that was first developed by Stephens (1971), van Imhoff (1988), or Chari and Hopenhayn (1991). More recently, this literature was extended to investigate the interactions between labor markets, demographic developments and social security systems in vintage models.

For instance, Mateos-Planas (2001) considers the effectiveness of schooling and technology-specific learning-by-doing. Boucekkine, de la Croix and Licandro (2002) define generation-specific human capital and analyze demographic phenomena (such as change in life expectancy) in an endogenous growth OLG setting. In this model, each generation is tied to its own vintage technology and accumulates purely vintagespecific human capital. The human capital vintage structure is regarded as an important ingredient to cover the aging effects of a non-homogeneous human capital stock for endogenous education and retirement decision, as well as for per capita growth.

In a model similar to Boucekkine et al. (2002) Echevaria and Iza (2007) include social security effects on education and retirement decision and analyze how life expectancy affects per capita growth. The problem of skill transferability between subsequent technology generations and the effects on the labor market are addressed by Violante (2002). One mechanism of his analysis is based on vintage-specific human capital. When separating in a labor market matching model workers can only partially transfer their skills to machines. This limited flexibility due to vintagespecific human capital increases wage losses upon separation.

Hornstein et al. (2007) build a matching model with vintage-specific human capital. 
The paper addresses changes in labor demand through changes in technology. In this model, the focus lies on frictions and the labor market matching process. The vintage structure of production contributes to the matching problem. Rather than emphasizing the firms' costs of "posting vacancies", the paper stresses the up-front, irreversible costs of investing in equipment as the typical vintage model. As a result, capital-embodied technological change reduces labor demand and raises equilibrium unemployment and the duration of unemployment.

Neither of these models, however, attempts to disentangle the effects of different types of education on different labor-market and welfare-state settings. Specifically, we distinguish between basic and general types of education and allow for replacement incomes and incomes in a no-skill service market. This allows us in particular to explain the (at least partial) inability of public education measures to overcome the challenges of aging societies when the statutory retirement age is raised to keep the pension system sustainable.

The paper proceeds as follows. In Section 2 we introduce a model of endogenous depreciation of human capital. In Section 3, we solve the model for the steady state. We determine the effects of the putty-putty technology and discuss the discarding of vintages, and thus, economic retirement of workers for three model variations. In Section 4, we present the effects of biased technical progress and changes of international prices with respect to the retirement age. Section 5 considers the education systems and education policies, while Section 6 concludes.

\section{A Human Capital Vintage Model}

Vintage models were introduced in the 1950s and 60s to analyze the effects of technological progress. In general, they are used where aggregate (closed) production functions with disembodied technologies do not seem to be appropriate for modeling the interaction between newly implemented capital, existing capital and new technologies. The most important difference to a closed-form aggregate production function is that the substitution process of factors is relatively more difficult for already installed production processes (in the past) than for production technologies currently in the process of implementation. In the real world technological advances are often implemented via new investments. Using these new technologies often requires an adaptation of production processes and skills. As technical progress does not just involve inventing a technology but also a diffusion through the production process, education and the structure of education play an important role for a society's ability to implement technical progress.

Figure 1 describes the overall idea of the decomposition of technologies used in the production of period $t$. Every period a new and improved technology is introduced. This technology is embodied in capital and linked to specific skills that run and utilize this new technology. This new technology, however, is only a fraction of all technologies. Existing older technologies are still in use. Current production still 
uses older technologies that were introduced in previous periods at $t-i$, such that even today's brand-new technology is aging and at a certain time $t-m$ will be discarded. A technology is fully depreciated when it is more efficient to allocate all flexible resources to newer and more efficient vintages.

[insert here Figure 1: Concept of vintage technologies and diffusion over time: In vintage models technology is not homogenous. Current production uses not only the just-installed newest technology, but also older technologies that were introduced in previous periods at $t-i$. However, even today's brand-new technology is aging and at time $t-m$ will be discarded. ]

In the following, we assume that technical progress can only be implemented if an adjustment in skills enables the use of a new generation (vintage) of technology. Moreover, we follow Mateos-Planas (2001) who suggests two hypotheses about the effects of education in the literature. One postulates that education provides a productivity advantage which is independent of experience. Education has not only a productivity effect and generates human capital. The other hypothesis suggests that education improves the ability of agents to adapt new technologies, hence education generates technological flexibility. Only this education effect makes it possible to combine new technologies with sufficiently educated labor to handle it. Hence, there is an important interaction between the implementation of new technologies and a reallocation in the labor market. The schooling system in our model addresses both aspects of education.

Schooling system: To determine domestic labor input, we need to characterize the workforce. The schooling process is modeled as a sequence of two education cycles. Initial schooling is followed by a lifelong learning program. All workers $N^{s}(v)$ of each vintage $v$ have to complete both education cycles. The number of workers in each vintage is constant.

Initial schooling equips workers with skills that enable them to use the most modern technology available when a new generation of workers enters the market. Apart from providing a basic educational grounding, these skills lead to a human capital endowment of workers that is related only to the most recent technology vintage introduced. Starting with initial schooling the human capital endowment of the workforce of each vintage is determined by the expenditure $R_{I}(t)$ on initial schooling and directly financed by share $\tau_{1}$ of total income $Y(t)$. Initial schooling is supposed to be equally successful for all, and hence equally spread over the whole workforce of each generation of workers when entering the labor market. 9 Thus, vintage-specific human capital endowment is generated linearly through spending a constant fraction $\varepsilon_{I}=\tau_{1}$ of income for a vintage entering the labor market. In vintage models time structure is complex. Thus, we need to distinguish vintages from

\footnotetext{
${ }^{9}$ This is the "neutrality hypothsis" in Mateos-Planas (2001). See also Lucas (1988), Grossman and Helpman (1991, Ch. 5) and others.
} 
periods in the past and relate them to the present time. There are two time indices in vintage-specific functions. The first index denotes the time of vintage installation and the second index denotes the current time of consideration. E.g. $h(v, t)$ denotes human capital endowment of a worker of vintage $v$ currently considered at time $t$; see also figure 1. Therefore, when entering the labor market at $t$ each worker is instantly endowed with a human capital $h(t, t)$ tied to the technology vintage of the period of their initial education. ${ }^{10}$

$$
h(t, t)=\frac{\varepsilon_{I} Y(t)}{N^{s}(t, t)}
$$

Note that $N^{s}(t, t)$ is a given number of workers entering the labor market at time $t$. As this number does not change over time we obtain $N^{s}(t, t)=N^{s}(v, t)$. The human capital endowment represents a particular labor productivity. Hence, $h(t, t)$ translates a physical hour of work into efficiency units. In case the economy grows exponentially, human capital endowment also grows exponentially due to the above linear investment pattern. Further, this basic human capital endowment is the asset the worker can offer on the labor market at any time.

In this model lifelong learning is a resource-absorbing schooling program. With a lifelong learning program workers are instructed to adjust to each following generation (most recent vintage) of technologies. As technical change is a continuous process every period all workers are invited to participate in the program no matter which vintage technology they currently use. Successful attendance of lifelong learning programs allows workers to adapt to the newest technology. ${ }^{11}$ Hence, successful attendance in a lifelong learning program enables to switch between all technology vintages installed. An established lifelong learning program helps aging workers to adapt to changing technologies. ${ }^{12}$ If a lifelong learning program is not successful for a worker, they can still use and handle the technology vintage they originally learned to use when they once entered the labor market as a young person.

While we assume that initial schooling is equally successful for all workers, the effects of the lifelong learning program are more complex.

First $N_{I I}^{s}(v, t)$ denotes the number of workers of each vintage $v$ for whom a lifelong learning program is successful when a new technology is introduced at time $t$. Second, the success of such a program positively depends on the resources $R_{I I}(t)$ spent

\footnotetext{
${ }^{10}$ Concerning this assumption Boucekkine, de la Croix and Licandro (2002) argue on page 343 that "... different generations have different learning experiences and ... the aggregate stock of human capital is built from the human capital of different generations. The most important characteristic of a growth theory designed to shed light on these issues is clearly to capture the vintage nature of human capital."

${ }^{11}$ This is the "learning hypothesis" in Mateos-Planas (2001) which refers to an education concept as suggested by Nelson and Phelps (1966), Welch (1970) and others.

${ }^{12}$ With this assumption we depart from Boucekkine, de la Croix and Licandro (2002) who define pure vintage-specific human capital and do not allow a switch from one to another technology vintage.
} 
at $t$ when a new technology is introduced. Even if all workers undergo both types of education, the success of the lifelong learning program depends on the distribution of the population's learning capabilities. Assuming they go through identical schooling, the results will vary according to the participants' learning abilities. Some workers are easily enabled to switch to every new technology as they have a general understanding of tasks, processes, job requirements and solutions. Other workers may have increasing difficulties adjusting to changing conditions; yet another group of workers - even if they have the same learning opportunities - will not be able to do anything else than execute the rather specific tasks they learned during their first education. These workers have no chance to switch to more sophisticated technologies. Further, the newer and more complex the technology, the more expenditure is needed to generate an ability to adjust. Hence this number of successfully educated workers $N_{I I}^{s}(v, t)$ depends on total spending and current complexity of the latest technology vintages when installed $\lambda(t, t)$. For simplicity we assume a linear relation $N_{I I}^{s}(v, t)=\frac{R_{I I}(t)}{\lambda(t, t)} \cdot{ }^{13}$ As expenditure $R_{I I}(t)$ is directly financed by fraction $\tau_{2}$ of total income $Y(t)$ the share of total income spend on lifelong learning is $\varepsilon_{I I}=\tau_{2}$ and the number of adaptable workers of each vintage $v$ is

$$
N_{I I}^{s}(v, t)=\frac{\varepsilon_{I I} Y(t)}{\lambda(t, t)},
$$

and dividing by the total number of workers $N^{s}(v, t)$ of vintage $v$ we can determine the share $q(v, t)$ of the workforce of a vintage that is flexible. If lifelong learning at $t$ is equally successful in all vintages and the number of workers are the same in each vintage, we can drop vintage index $v$

$$
q(t)=q(v, t)=\frac{N_{I I}^{s}(v, t)}{N^{s}(v, t)}=\frac{\varepsilon_{I I} Y(t)}{\lambda(t, t) N^{s}(v, t)} .
$$

For the remaining fraction of workers $1-q(t)$ investments in the lifelong learning program are not sufficient to generate the ability to switch to the most recent vintage of technologies. The number of these workers is

$$
N_{I}^{s}(v, t)=N^{s}(v, t)-N_{I I}^{s}(v, t)=(1-q(t)) N^{s}(v, t) .
$$

Even if these workers can still offer their existing human capital acquired during initial schooling, their human capital is connected to the vintage-specific technology and hence remains a vintage-specific human capital $h(t, t)$ throughout their entire economic life.

To summarize, the schooling system is a sequence of two cycles. First, each vintage generation obtains initial schooling during the period of market entry. Second, in every year until retirement each vintage participates in the lifelong learning program in which a share $q(t)$ of each vintage learns to adjust to new technologies.

\footnotetext{
${ }^{13}$ Anonther explicit example for such a schooling function could be $q=\left(R_{I I}\right)^{\varphi}$, with $\varphi<1$. However, here we keep the simple linear relation.
} 
Labor market: The effects of the lifelong learning program together with the distribution of abilities among the population have created two labor market segments.

First, the two education cycles lead to a workforce offering vintage-specific skills. Education efforts for lifelong learning are not sufficiently effective to enable these workers to adapt other technologies than the ones they learned to use during initial schooling. Therefore, these workers continue to use the same technology throughout their working life. The human capital level of a whole vintage is the human capital endowment multiplied by the number of workers using vintage-specific skills: ${ }^{14}$

$$
H(t, t)=h(t, t) N_{I}(t, t) .
$$

While in traditional vintage models the technology can be represented by real capital, here vintage-specific human capital characterizes a certain production process and technology. Again, assuming again perfectly competitive markets, a vintage of this type of labor [workers with identical efficiency] is - due to downward competition - either fully demanded and employed or fully unemployed. If a vintage is fully demanded, we obtain $N_{I}^{d}(v, t)=N_{I}^{s}\left((v, t)=N_{I}(v, t)\right.$. If profits of a vintage turn negative when employing $N_{I}^{d}(v, t)$ this vintage is discarded (see scrapping rule eq 14). Hence, not one of these workers is employed, $N_{I}^{d}(v, t)=0$. If workers are tied to their technology vintage we have a vintage-specific segmentation of the labor market in which either $N_{I}(v, t)$ is still sufficiently productive to remain in demand, or not.

With $m(t)$ generations of technologies in use at time $t$, we obtain a demand for $m(t)$ vintages of labor with vintage-specific skills. In general, at different points in time the number of vintages in use could differ, thus $m(t)$ depends on time. However, later when we solve for a stationary state economy, $m(t)$ takes the stationary $m^{*}$. Hence, from today's perspective at $t$ we sum up from $t-m(t)$ to $t$ in order to collect all vintages $N_{I}^{d}(v, t)$ to obtain total vintage-specific labor demand $N_{I}^{d}(t)$ as

$$
N_{I}^{d}(t)=\int_{t-m(t)}^{t} N^{d}(v, t) d v .
$$

Denoting $T$ as the statutory retirement age, $T$ vintages are supplied. From today's perspective at $t$ we have to sum up from $t-T$ to $t$ in order to collect all vintages of vintage-specific labor supplied. As in each vintage $1-q$ is the share of vintagespecific workers and $N^{s}(v, t)$ is the given number of workers of a vintage, the supply of vintage-specific workers of each vintage is $N_{I}^{s}(v, t)=(1-q(t)) N^{s}(v, t)$. The

\footnotetext{
${ }^{14}$ Note that $H(t, t)$ is the value of human capital of vintage $t$ (first index) at time $t$ (second index). Therefore, in general we can describe the value of any vintage $v$ by applying the same specification. Human capital of any vintage $v$ is built by investing share $\varepsilon_{I}$ of income of that vintage $Y(v)$. Further, if we look at human capital of any vintage $v$ from the perspective of time $t[H(v, t)]$ we know that human capital per capita is built by the investment process $h(v, t)=\frac{\varepsilon_{I} Y(v)}{N^{s}(v, t)}$. (eq 1$)$. Hence, $H(v, t)=h(v, t) N_{I}(v, t)$.
} 
economic reason is simple. For a constant population and a stationary education policy the constant population of each vintage is turned into a constant fraction of each type of workers. Hence, total supply of workers with vintage-specific skills $N_{I}^{s}(t)$ adds to

$$
N_{I}^{s}(t)=\int_{t-T}^{t}(1-q(t)) N^{s}(v, t) d v=(1-q(t)) N^{s},
$$

where $N^{s}=T N^{s}(v, t)=1$. Note that as education effects do not change over time and per vintage, the share $q(t)$ will turn constant in steady state; however, in general it depends on time.

As aggregate demand $N_{I}^{d}(t)$ and supply $N_{I}^{s}(t)$ of vintage-specific labor adds over all vintages, $T$ vintages are in supply. This implies that in the labor market for vintage-specific workers, full employment requires that all $T$ vintages in supply must be demanded. While $T$ is politically determined $m(t)$ is the endogenous economic retirement age. If fewer vintages are demanded than supplied $[m(t) \leqq T]$, workers of these vintages are not employed and we obtain unemployment in the labor market for vintage-specific workers. Therefore, we must study the conditions which determine $m(t)$ to understand how $m(t)$ can be adjusted to match the politically desired $T$. Otherwise, vintage-specific human capital fully depreciates too early.

Second, another segment of the labor market consists of adaptable labor. For these workers $N_{I I}^{s}(v, t)$ the present level of spending on the lifelong learning program is successful. If the lifelong learning program is successful, a worker is able to adapt new technologies and hence can switch to any new generation of technologies efficiently.

Thus technology $\lambda(v, t)$ is modeled as efficiency index that augments this type of labor. ${ }^{15}$ At time $t$ labor with flexible skills employed in the technology vintage $v$ in efficiency units is

$$
\Lambda(v, t)=\lambda(v, t) N_{I I}^{d}(v, t)
$$

This point is different in standard modeling with an aggregate production function. In a standard aggregate production function, a change in the technology index is modeled as if it improves all technology vintages in use at no cost. However, normally a technical improvement is introduced through the currently installed technical vintage, and this new technology does not directly affect the efficiency of

\footnotetext{
${ }^{15}$ Note again the notation of $\lambda(v, t)$. The first index identifies the vintage $v$ when this technology was installed and the second index describes the current time of consideration. What does this mean? Is there an easy example? As we look at a growth model we can think of a continuous technical change by the percentage rate $\hat{\lambda}$ (in fact we do so in this model below). Then, technology index $\lambda$ will grow continuously and exponentially. If we are currently at $t$, the index has the current value $\lambda(t)$. If we compare $v$ with today we obtain $\lambda(v, t): \lambda(t)=\lambda(0) e^{\hat{\lambda} t}, \lambda(v)=\lambda(0) e^{\hat{\lambda} v}$ and hence: $\lambda(v, t)=\frac{\lambda(0) e^{\hat{\lambda} v}}{\lambda(0) e^{\hat{\lambda} t}}=e^{-\hat{\lambda}(t-v)}$.
} 
older technologies still in use. In aggregate production functions this explicit time structure is disregarded as adjustment is assumed to be perfect and costless. In our model, however, progress enters only through the newest vintage. Therefore, there is an efficiency structure with respect to time when looking at all vintages still in use, and this time structure matters. The most modern vintage has the highest efficiency. Further, the change of efficiency of this period to the next future period's technology is given by a constant percentage rate $\hat{\lambda}^{16}$ This rate is identical for all vintages when installed,

$$
\hat{\lambda}:=\frac{\dot{\lambda}(t)}{\lambda(t)}=\frac{\dot{\lambda}(v)}{\lambda(v)}=\text { const }
$$

In this simple case, technical change happens exogenously and grows exponentially. Obviously technology could be made endogenous and technical change could depend on other variables in various functional forms. However, for simplicity we assume technical change to be a given constant rate. ${ }^{17}$ Since technological progress is embodied, $\lambda(v, t)$ will affect only the current production vintage, not existing production processes. This is a major difference of vintage technologies compared to simple aggregate production functions.

Adaptable labor is demanded by the newest $m(t)$ technologies. With $T$ as the total economic lifetime (given by the statutory retirement age), labor supply consists of $T$ vintages. Thus, aggregate demand and aggregate supply of flexible labor is

$$
N_{I I}(t)=\int_{t-m(t)}^{t} N_{I I}^{d}(v, t) d v=\int_{t-T}^{t} q N^{s}(v, t) d v=q N^{s} .
$$

As we assume perfectly competitive markets, workers descending from $T$ vintages will be in demand due to the newest technologies $m(t)$. Thus, these workers will never be unemployed. Their retirement usually begins when they reach statutory retirement age, which is here equivalent to $T$.

Production: In a vintage approach the implementation of technical changes is more complex than defined by a closed (aggregate) production function. When introducing a vintage model we have to consider the substitution possibilities ex post and ex ante. For a given vintage technology, the inputs of production can easily be substituted ex ante, while there are limited substitution possibilities ex post. To avoid results that are due to fixed input relations, we use a putty-putty vintage approach. Specifically, we assume that the elasticity of substitution ex ante is higher than the elasticity of substitution ex post. Thus, the model is a combination of the putty-putty approach first modeled by Solow (1960) and the putty-clay approach first modeled by Johansen (1959) and Salter (1960). ${ }^{18}$ The putty-putty model below

\footnotetext{
${ }^{16}$ In general we use "^" notation and hence obtain $\hat{x}=\frac{d \ln (x(t))}{d t}=\frac{\dot{x}}{x}$

${ }^{17}$ See de Mello (1995) or Boucekkine, Licandro, Puch and del Rio (2005) for endogenous growth conditions in vintage models.

${ }^{18}$ Putty-putty models with limited substitution possibilities ex post can be found in Scheper (1968), Zon (1994), and Meijers and Zon (1994), or Gilchrist and Williams (2005).
} 
allows for substitution and also describes an obvious adaptation and adjustment problem generated by the technical requirements for adjusting technologies introduced in the past.

The production ex ante and ex post is modeled by a nested CES function. Aggregate output at time $t, Y(t)$, is the sum of vintage outputs, $Y(v, t)$, producing

$$
Y(t)=\int_{t-m(t)}^{t} Y(v, t) d v
$$

where $m(t)$ is the age of the oldest technology in use. At time $t$ vintage output $Y(v, t)$ of the vintage installed at $v$ is produced with imports $I m$ and domestic labor services $S$. At the time of installing a new technology, ex ante, the elasticity of substitution is $\sigma_{1}:=\frac{1}{1+\rho_{1}}$ such that we arrive at

$$
Y(t, t)=\left(\gamma \operatorname{Im}(t, t)^{-\rho_{1}}+(1-\gamma) S(t, t)^{-\rho_{1}}\right)^{-\frac{1}{\rho_{1}}}
$$

The already installed production process is more difficult to adjust. Ex post the inputs cannot be substituted to the same extent as ex ante. Thus, the elasticity of substitution ex post $(v<t)$ is $\sigma_{2}=\frac{1}{1+\rho_{2}}$ with $\sigma_{1}>\sigma_{2}$ and

$$
Y(v, t)=\left(\gamma_{v} \operatorname{Im}(v, t)^{-\rho_{2}}+\delta_{v} S(v, t)^{-\rho_{2}}\right)^{-\frac{1}{\rho_{2}}} .
$$

Defining the elasticity of production for domestic labor services ${ }^{19}$ as $\eta_{Y(t, t), S(t, t)}$ the following two conditions ensure that the relation of factor productivity does not change for the technology after it has been installed: ${ }^{20}$

$$
\begin{aligned}
\eta_{Y(t, t), S(t, t)} & =\lim _{v \rightarrow t} \eta_{Y(t, v), S(t, v)}, \\
Y(t, t) & =\lim _{v \rightarrow t} Y(v, t) .
\end{aligned}
$$

Formally, a continuous differentiable relation between the ex post and the ex ante production function is guaranteed. $\gamma_{v}$ and $\delta_{v}$ are determined depending on the parameters $\gamma$ and $1-\gamma$.

Labor services: The supply of labor services is modeled with a labor service production function. Here again, a putty-putty technology with different elasticities of substitution ex ante and ex post is considered. The ex ante production of labor services is assumed to be of the Cobb-Douglas type, hence at the time of installation, labor services from vintage-specific human capital $H(t, t)$ (see eq. 3) and adaptable

\footnotetext{
${ }^{19}$ Note, $\eta_{Y(t, t), S(t, t)}=\frac{d Y(t, t)}{d S(t, t)} \frac{S(t, t)}{Y(t, t)}=\left(\gamma \operatorname{Im}(t, t)^{-\rho_{1}}+(1-\gamma) S(t, t)^{-\rho_{1}}\right)^{-1}(1-\gamma) S(t, t)^{-\rho_{1}}$ $\eta_{Y(t, v), S(t, v)}=\frac{d Y(t, v)}{d S(t, v)} \frac{S(t, v)}{Y(t, v)}=\left(\gamma_{t} \operatorname{Im}(t, v)^{-\rho_{2}}+\delta_{t} S(t, v)^{-\rho_{2}}\right)^{-1} \delta_{t} S(t, v)^{-\rho_{2}}$

${ }^{20}$ There are no jumps between already installed vintages and vintages entering the market.
} 
labor in efficiency units $\Lambda(t, t)$ (see eq. 4) are easy to substitute. The elasticity of substitution is $\sigma_{3}=1$,

$$
S(t, t)=H(t, t)^{1-\alpha} \Lambda(t, t)^{\alpha} .
$$

A moment after installation (ex post) production inputs $H(v, t)$ are still substitutes. However, the elasticity of substitution ex post is assumed to be smaller than ex ante: $\sigma_{4}:=\frac{1}{1+\rho_{4}}<\sigma_{3}=1$. For the labor services we obtain

$$
S(v, t)=\left(\alpha_{v} \Lambda(v, t)^{-\rho_{4}}+\beta_{v} H(v, t)^{-\rho_{4}}\right)^{-\frac{1}{\rho_{4}}}
$$

for $v<t$. Denoting $\eta_{S(t, t), N_{I I}(t, t)}$ as elasticity of service production with respect to flexible labor ${ }^{21}$, the following two conditions guarantee that the relation of productivity does not change when moving from ex ante to ex post service production:

$$
\begin{aligned}
\eta_{S(t, t), N_{I I}(t, t)} & =\lim _{v \rightarrow t} \eta_{S(t, v), N_{I I}(t, v)} \\
S(t, t) & =\lim _{v \rightarrow t} S(v, t) .
\end{aligned}
$$

Thus, $\alpha_{v}$ and $\beta_{v}$ are determined endogenously.

To complete the model we need to discuss the conditions that would discard a technology vintage. We suggest to consider three variations of scrapping rules to allow for a rich discussion.

(i) Unrestricted discarding of a technology vintage: If we emplace no restrictions the scrapping rule is straightforward. A vintage is discarded after $m(t)$ vintages if the profits of the vintage vanish (see Benhabib and Rustichini, 1993, and van Hilten, 1991, for scrapping rules), i.e. the income of vintage-specific human capital is zero. Formally, income of vintage-specific labor $w_{V}(v, t)$ has two components, the rental rate of vintage-specific human capital $r(v, t)$ and the human capital endowment $h(v, t)$. This is earned as long as the vintage is still in use. After $m(t)$ periods income of vintage-specific human capital turns to zero and this vintage is discarded, $w_{V}(t-m(t), t)=r(t-m(t), t) h(t-m(t), t)=0$. How should that happen? If we consider identical firms of a vintage and denote $Y(t-m(t), t)$ as the value of production, $p$ as given price for imports $\operatorname{Im}(t-m(t), t)$ and $w(t)$ as wages for flexible workers, firms can only survive as long as they have non-negative profits

$$
\Pi(v, t)=Y(v, t)-p I m(v, t)-w(t) N_{I I}^{d}(v, t)-r(v, t) h(v, t) N_{I}^{d}(v, t) \geqq 0 .
$$

Therefore, as long as all factors of production can be compensated out of firms' revenues, this vintage will remain in service. However, when compensating factors of

\footnotetext{
${ }^{21}$ Note, $\eta_{S(t, t), N_{I I}(t, t)}=\frac{d S(t, t)}{d N_{I I}(t, t)} \frac{N_{I I}(t, t)}{S(t, t)}=\alpha$

$\eta_{S(t, v), N_{I I}(t, v)}=\frac{d S(t, v)}{d N_{I I}(t, v)} \frac{N_{I I}(t, v)}{S(t, v)}=\alpha_{v} \lambda(v, t)^{-\rho_{4}}\left(\frac{S(v, t)}{N_{I I}^{d}(v, t)}\right)^{\rho_{4}}$
} 
production the time structure of the model implies asymmetries and segmentation. First, substitutability is less for installed vintages (ex post) than ex ante. Second, the only factor of production that is fully tied to a vintage is vintage-specific human capital. Imports and flexible labor can be allocated over all vintages. Further, wages for flexible labor are determined in a labor market with all vintages in use. Hence, these wages must equalize and determine the respective flexible labor demand in each vintage. Therefore, in order to keep a vintage in business firms have to ensure that they first compensate the factors of production which compete with other vintages. What is left can be spent on vintage-specific labor in the labor market segment of that vintage. Hence, these revenue residuals determine the rental rate of vintagespecific human capital. Further, factor demands in a vintage and rental rates are not constant over time. Due to optimal factor allocation decisions for each vintage, human capital rental rates of older vintages receive continuously less pay (see figure $3)^{22}$ as the other flexible factors absorb more and more of the revenues. Therefore, a vintage is discarded if the positive profit condition does not allow positive payments for the vintage-specific factor.

$$
Y(t-m(t), t)-p I m(t-m(t), t)-w(t) N_{I I}^{d}(t-m(t), t)=0 .
$$

This scrapping rule determines the economic scrapping time $m(t)$ of a technology vintage. Even if the technology physically still exists and functions, a technology is economical fully depreciated if it is no longer able to contribute to profits. This case is interesting - albeit unrealistic - as it shows that a technology vintage and the vintage-specific human capital will be completely dismissed even if they are available at no cost. Therefore, this case addresses the argument that it is only a question of the level of compensation whether a resource is employed. That is, a technology vintage would not be further employed than the scrapping time $m(t)$, even at zero pay for the respective vintage-specific human capital. In the subsequent section we show that there is a stationary solution for this scrapping time such that $m(t)=m^{*}$. Hence, the stationary number of not-employable vintages $\left(T-m^{*}\right)$ and by that the total rate of not-employable labor ${ }^{23}$ is

$$
u=\left(1-\frac{m^{*}}{T}\right)(1-q)
$$

(ii) Discarding a technology vintage under the condition of social transfers: Rule (14) is not the only possible consideration with respect to discarding a technology vintage. In reality firms' labor demand cannot drive down compensations for vintage-specific human capital to zero. In real economies workers with vintage-specific human capital may have outside options which can be included by means of a simple model variation.

\footnotetext{
${ }^{22}$ In fact, the full mechanism can be seen only after having solved the model for steady state. However, at this point it seems important to obtain a first intution about the way the model works.

${ }^{23}$ Note that $u(t)=U(t) / N^{s}$, with $N^{s}=1$.
} 
With $w_{V}(t-m(t), t)$ as a wage for vintage-specific human capital for vintage $t$ $m(t)$ at time $t$ we obtain again $w_{V}(t-m(t), t)=r(t-m(t), t) h(t-m(t), t)$. An interesting outside option to consider is a given transfer payment $\theta$ for a notemployed older worker. For such transfer $\theta$ workers of a vintage remain in productive activities as long as the respective wages $w_{V}$ are higher than the transfer $w_{V}(t-$ $m, t) \geq \theta$, and the scrapping rule becomes

$$
w_{V}(t-m, t)=\theta
$$

However, this model variation is incomplete if we do not talk about financing. If the just discarded vintage is $m^{1}, T-m^{1}$ vintages are not productively employed and receive transfer payments $\theta U$. In addition to lump sum taxes $\left(\tau_{1}, \tau_{2}\right)$ to finance education, we now need to finance early retirement transfers out of the overall income. To make the modeling as simple as possible, we assume that workers receiving transfers obtain identical payments, such that total spending for all non-employed labor adds to $\theta U=\theta\left(1-\frac{m}{T}\right) T N^{s}(v)(1-q)$. This amount has to be collected through taxes with the tax for transfer rate $\tau_{t r}$. In order to complete this model variation, we further assume that total transfer income is fully spent on the final product, such that this fraction of production is also fully demanded.

(iii) Discarding a technology vintage when a no-skill service sector exists: So far this model has been described as an aggregate production process with one sector of production. This sector produces with (industrial) production technologies and requires skilled labor. We now call this a "sector technology-using sector" $\mathrm{Y}(\mathrm{t})$ as discussed in the sections above. So far the only outside option for an aging worker with endogenously depreciating human capital and a declining income profile was a transfer payment. However, an additional option is to switch to another labor market segment, the no-skill market segment. If rewards for vintage-specific human capital $w_{V}$ drop below no-skill wages $w_{S}$, the second outside option for such workers is to take a no-skill job. In this variation of the model we suggest the existence of a no-skill service sector as a second final good sector.

The service sector produces purely with labor, has no skill requirements and recruits labor by competing with the technology-using sector for any kind of labor. The income and production value of this service sector is $Y_{S}(t)$ and the demand is described by absorbing a given fraction $c_{S}$ of total disposable income $Y_{D}(t)$. Disposable income is the after-tax income of both sectors, the technology-using sector $Y(t)$ and the no-skill service sector $Y_{S}(t)$, that is $Y_{D}(t)=\left(1-\tau_{1}-\tau_{2}\right)\left(Y(t)+Y_{S}(t)\right)$. Hence, equilibrium in the service sector requires $Y_{S}(t)=c_{S}\left(1-\tau_{1}-\tau_{2}\right)\left(Y(t)+Y_{S}(t)\right)$ and the equilibrium income relation between service and technology-using sector becomes $Y_{S}(t)=\frac{c_{S}\left(1-\tau_{1}-\tau_{2}\right)}{\left(1-c_{S}\left(1-\tau_{1}-\tau_{2}\right)\right)} Y(t)$. As a result, $T-m$ vintages can be attracted for work in the no-skill service sector. In the no-skill service sector the only factor of production is labor. Hence, all factor income is labor income, such that this labor income per vintage is $\frac{Y_{S}(t)}{T-m}$. To obtain the no-skill wage rate we need to divide the labor income 
of the service sector by the number of workers and obtain

$$
w_{S}=\frac{\frac{c_{S}\left(1-\tau_{1}-\tau_{2}\right)}{\left(1-c_{S}\left(1-\tau_{1}-\tau_{2}\right)\right)} Y(t)}{\left(1-\frac{m}{T}\right)(1-q)} .
$$

$w_{S}$ is an increasing function of employed vintages in the technology-using sector. The more vintages are discarded in the technology-using sector the more vintages compete for jobs in the no-skill sector and the lower the potential wages that can be paid in the no-skill service sector. However, determining the service sector wage leads back to the scrapping rule,

$$
w_{V}(t-m, t)=w_{S}(m)
$$

The switching of labor from the technology using sector to the no-skill service sector and the respective graphic representation is discussed below in figure 2c.

\section{Solution of the Model}

In line with neoclassical exogenous growth models we determine the conditions for a stationary economy in which fundamental aggregate variables grow with exogenous identical rates of technical change and fundamental structural variables remain stationary. However, for this stationary world we can identify a stationary time when technology vintages are endogenously discarded and respective vintage-specific human capital fully depreciates. In order to do this, we first look at conditions for efficient allocation and second, use them for determining the scrapping time.

\section{Solving for efficient factor allocation:}

With a putty-putty technology, the efficient allocation of inputs can be divided into two parts. (i) Optimal human capital and optimal import intensity are chosen by maximizing the profits of employing vintage-specific human capital when installing a new technology. (ii) Since the production factors can be substituted ex post, the relation of the inputs is chosen optimally after installing a technology. While imports and adaptable workers are paid according to their marginal product, vintage-specific human capital and the respective workers receive the residual income determined in a zero profit market equilibrium. Please note that the scrapping time $m(t)$, the time when vintage-specific human capital is discarded, is not a choice variable when determining profit maximizing factor inputs. $m(t)$ is determined endogenously by the non-profit condition. A vintage is discarded as soon as the rental rate of human capital of a vintage is zero. ${ }^{24}$

\footnotetext{
${ }^{24}$ See equations 14 and 23.
} 
(i) Let $p$ be the price of imports. Adopting the small country assumption, $p$ is regarded as exogenous. The profits of employing vintage-specific human capital at time of installation are

$$
\Pi(t)=\int_{t}^{t+m}\left(Y(t, v)-p I m(t, v)-w(t) N_{I I}^{d}(t, v)\right) e^{-r(v-t)} d v-H(t, t),
$$

where $r$ is the quasi-rent of vintage-specific human capital and $w$ the wage rate of adaptable labor. Writing this equation in intensity form through dividing by $N_{I I}^{d}(t, t)$ we obtain $\left(\pi(t):=\frac{\Pi(t)}{N_{I I}^{d}(t, t)}, y(t, v):=\frac{Y(t, v)}{N_{I I}^{d}(t, v)}, \kappa(t, t):=\frac{H(t, t)}{N_{I I}^{d}(t, t)}, i m(t, v):=\frac{\operatorname{Im}(t, v)}{N_{I I}^{d}(t, v)}\right)$ :

$$
\pi(t)=\int_{t}^{t+m} \frac{N_{I I}^{d}(t, v)}{N_{I I}^{d}(t, t)}(y(t, v)-p i m(t, v)-w(t)) e^{-r(v-t)} d v-\kappa(t, t) .
$$

The optimal vintage-specific human capital intensity at the time of installation is obtained from the f.o.c.,

$$
\frac{\partial \pi(t)}{\partial \kappa(t, t)}=0 \Longleftrightarrow \int_{t}^{t+m} \frac{N_{I I}^{d}(t, v)}{N_{I I}^{d}(t, t)}\left(\frac{\partial y(t, v)}{\partial \kappa(t, t)}\right) e^{-r(v-t)} d v=1
$$

and the optimal import intensity is

$$
\frac{\partial \pi(t)}{\partial i m(t, t)}=0 \Longleftrightarrow \int_{t}^{t+m} \frac{N_{I I}^{d}(t, v)}{N_{I I}^{d}(t, t)}\left(\frac{\partial y(t, v)}{\partial i m(t, t)}-p \frac{\partial i m(t, v)}{\partial i m(t, t)}\right) e^{-r(v-t)} d v=0 .
$$

(ii) Having installed a technology, the inputs are inserted efficiently by maximizing the profits of every technology vintage with $(v=$ installing time, $t=$ present time)

$$
\Pi(v, t)=Y(v, t)-p I m(v, t)-w(t) N_{I I}^{d}(v, t)-r(v, t) H(v, t) .
$$

$r(v, t)$ is the vintage rental rate of vintage-specific human capital determining the payment flow of the respective workers of vintage-specific labor. Since human capital is tied to a certain vintage and no internal depreciation of human capital is considered, we have $H(v, t)=H(v, v)$. By contrast, adaptable labor and imports inserted in a certain technology can change after installing a technology. Thus, we use the following two f.o.c.s to maximize the profit for each vintage. Imports are allocated efficiently ex post such that for $v<t$ we obtain ${ }^{25}$

$$
\frac{\partial \Pi(v, t)}{\partial \operatorname{Im}(v, t)}=0 \Longleftrightarrow \frac{\partial Y(v, t)}{\partial \operatorname{Im}(v, t)}=p .
$$

Workers with adaptable technological skills are also allocated efficiently ex post:

$$
\frac{\partial \Pi(v, t)}{\partial N_{I I}^{d}(v, t)}=0 \quad \Longleftrightarrow \quad \frac{\partial Y(v, t)}{\partial N_{I I}^{d}(v, t)}=w(t) .
$$

\footnotetext{
${ }^{25}$ For $v=t$ this condition is equivalent to equation (19) - see Corollary 5.
} 
The rental rate of vintage-specific human capital is determined by the zero-profit condition:

$$
\Pi(v, t)=0 \Longleftrightarrow r(v, t) H(v, t)=Y(v, t)-p \operatorname{Im}(v, t)-w(t) N_{I I}^{d}(v, t) .
$$

Using Euler's theorem, (22) can be written as

$$
\frac{\partial \Pi(v, t)}{\partial H(v, t)}=0 \quad \Longleftrightarrow \quad \frac{\partial Y(v, t)}{\partial H(v, t)}=r(v, t) .
$$

In the following section we solve the model for the three variations of scrapping rule which should be considered in a further discussion of comparative statics and education policies.

\section{Solving for the time of discarding a technology vintage:}

(i) Unrestricted discarding: We solve the model for the steady state. ${ }^{26}$ To show the effects of the putty-putty technology, we focus on the development of the variables of one vintage. Equations (5)-(14) and optimal choices (eqs. (18)-(22)) determine the growth path of the endogenous variables. Due to its structure, the model can be written in intensity form. The economy is in steady state if the demand for adaptable labor of a new technology $N_{I I}^{d}(t, t)$ is constant - we do not consider population growth - and vintage-specific human capital and imports grow at the rate of exogenous technological progress $\hat{\lambda}$. It follows that the vintage output $y(t, t)$, the aggregate output $y(t)$, domestic labor services $s(t, t)$, and the wage rate of adaptable labor grow at the rate $\hat{\lambda}$, while the scrapping time $m$, the coefficients $\delta_{t}, \gamma_{t}, \alpha_{t}, \beta_{t}$ as well as the quasi-rent $r$ are constant in steady state. ${ }^{27}$

Formally the model is solved in three steps. First, the scrapping time $m^{*}$ is determined. A vintage is discarded if the rental rate of human capital of a vintage $r\left(t, t+m^{*}\right) H(t, t)=Y\left(t, t+m^{*}\right)-p I m\left(t, t+m^{*}\right)-w\left(t+m^{*}\right) N_{I I}^{d}\left(t, t+m^{*}\right)$ is zero.

The condition is determined by the structure of the growth rates in steady state. $m^{*}$ is not dependent on the level of the output or the intensities of the model. Thus, the stationary scrapping time is ${ }^{28}$

$$
m^{*}=\frac{\ln \left[\left(1-\left(\frac{\gamma}{p}\right)^{\frac{1}{1+\rho_{1}}}\right)^{-1} \alpha\right]}{-\hat{\lambda}} \frac{1+\rho_{4}}{\rho_{4}} .
$$

\footnotetext{
${ }^{26}$ For the convenience of the reader all relevant theorems and lemmas are presented in the appendix.

${ }^{27}$ The coefficients $\delta_{t}, \gamma_{t}, \alpha_{t}, \beta$ are determined in Lemma 1. Wage of adaptable labor the fact that vintage output and wages grow at identical rates is derived in corollary 4. Lemma 9 solves for the aggregate output $y$, and in theorem 6 we determine the steady state scrapping time $m$. The quasi rent of human capital is derived in theorem 10 .

${ }^{28}$ See Theorem 6.
} 
Second, to obtain the remaining variables, human capital intensity and the quasirent have to be determined. Depending on $\kappa$ the growth path of the variables follows immediately. See Lemma 2, Corollary 3 for the output, the imports and the wage rate of flexible labor. The rest follows from the definition of the variables and Lemma 1. Human capital intensity and the quasi-rent of vintage-specific human capital are determined through the supply of and demand for vintage-specific human capital given in equations (1) and (18). In theorem 10 it is shown that unique values of $\kappa$ and $r$ follow if the rate of initial schooling is not too high $\left(\tau_{1}<\tau_{1}^{\max }\right) \cdot{ }^{29}$

Third, developments of the variables of a certain vintage are determined: the demand for adaptable labor, the vintage output of a certain technology, and the employment of vintage-specific human capital and the respective workers.

[here insert Figure 2: Employability and allocation path of adaptable labor and labor with vintage-specific human capital. Diagram (a) shows that older vintages employ less and less adaptable labor $N_{I I}^{d}$. Diagram (b) indicates that labor with vintage-specific human capital is fully employed as long as the technology vintage is in use. For discarded vintages, the respective labor with vintages-specific skills is unemployed if the scrapping time is before statutory retirement age, $m<T]$

The demand for adaptable labor of the technology installed in $v$ at time $t$ is $^{30}$

$$
N_{I I}^{d}(v, t)=\left(\frac{\left(\frac{w(t)}{c_{2} \alpha_{v} \lambda(v)^{-\rho_{4}}}\right)^{-\frac{\rho_{4}}{1+\rho_{4}}}-\alpha_{v} \lambda(v)^{-\rho_{4}}}{\beta_{v}}\right)^{\frac{1}{\rho_{4}}} H(t, t) .
$$

Figure 2a shows that the demand for adaptable labor declines as a vintage ages. Due to condition (21), the wage rate of adaptable labor equals the marginal productivity of adaptable labor and must be equal across vintages. At the same time, technological progress increases the productivity of adaptable workers in younger vintages. Therefore, the number of adaptable workers employed decreases as vintages age (see figure 2a). When a technology is discarded after $m^{*}$ vintages, the demand for adaptable labor is positive. ${ }^{31}$ The economic lifespan of adaptable workers has not yet ended - they may continue to work until the statutory retirement age.

Unlike adaptable labor, workers using vintage-specific skills are tied to a specific technology. Hence, each vintage of workers tied to the respective technology vintage is employed as long as the technology is not discarded. Figure 2b illustrates this mechanism. In case the scrapping time of a vintage is below statutory retirement age, these vintages are no longer employable.

[here insert Figure 3: Income of labor with vintage-specific human capital and adaptable labor for different model variations. Diagrams (a,b,c) show that wages

\footnotetext{
${ }^{29}$ If this condition does not hold, the quasi-rent $r$ will be negative.

${ }^{30}$ Using Lemma 2 this condition follows from equation (21).

${ }^{31}$ See Lemma 8.
} 
for adaptable labor $w(t)$ increase with the rate of technical progress, while wages for labor with vintage-specific skills $w_{V}$ decline with the aging technology. In diagram (a) unemployment occurs if a vintage and the respective vintage-specific labor is discarded even on a zero wage. (b) shows that social benefits at level $\theta$ may discard a vintage even before that. (c) describes the switch of labor with vintages-specific skill to a no-skill service sector with wage $w(m)$. ]

With adaptable workers allocating themselves to the most efficient and hence more recent technologies and labor being tied to a specific technology, input of adaptable labor decreases as vintages age, $\kappa(v, t)$. The ratio of vintage-specific human capital to adaptable workers increases. Accordingly, the productivity of vintage-specific human capital decreases as technologies become older. In figure 3 we show the wage rate of vintage-specific human capital $w_{V}(t-m, t)$ and wages of adaptable labor $w(t)$ for the three discarding rules discussed above. Figure 3a represents the graph for the unrestricted case analytically determined by (23). Since $w_{V}$ is determined as residual income, lower output and higher wages for adaptable workers imply that $w_{V}(t-m, t)$ will decrease as a vintage ages. Thus, the income of workers using vintage-specific skills decreases as they become older. The wage gap increases. These results are exactly in line with the findings of Violante (2002, p. 302) who states "... workers learn vintage-specific skills and, when separating, they can only partially transfer their skills across machines. A technological acceleration has two effects. First, it reduces skill transferability thereby increasing wage losses upon separation. ...". Even more, a technology and human capital vintage is scrapped when the income of these workers is zero $\left(w_{V}(v, v+m)=0\right.$, see figure 3a or condition (23)). Full depreciation of human capital determines the economic retirement age of these workers. In figure 3a, older vintages are fully depreciated even if they have not reached the statutory retirement age, and would not be employable even at a zero wage.

Unlike the statutory retirement age, the effective economic retirement age $m^{*}$ is endogenous and not under direct political control. A politically determined increase in the statutory retirement age $T$ can only be a successful strategy as long as the statutory retirement age is below the economically determined time of full depreciation of vintage-specific human capital $\left(T<m^{*}\right)$. Full depreciation of vintage-specific human capital means that even at a zero wage, these workers are not employable. The reason for this market failure is a rigidity generated by the vintage structure of the technology, which lies in the past of the appearance of this market problem. Hence, the described mechanism generates a phase at the end of working life in which this kind of labor is permanently not-employable. The level of not-employable labor due to this kind of mechanism is ${ }^{32}$

$$
\begin{gathered}
u=\left(1-\frac{m}{T}\right)(1-q) . \\
{ }^{32} U(t)=N_{I}^{s}-N_{I}^{d}+N_{I I}^{s}-N_{I I}^{d}, \quad U(t)=\frac{(t-m)(1-q) N_{V}^{s}-(t-T)(1-q) N_{V}^{s}}{N^{s}}=\left(1-\frac{m}{T}\right)(1-q) .
\end{gathered}
$$


As a discarded vintage will never be employed again, the scrapping time also determines the duration of this phase at the end of the working life of this kind of labor. Hence, this approach also sheds some light on the widely observed long-term unemployment among older workers.

(ii) Discarding under the condition of social transfers: Unrestricted discarding of a technology vintage will lead to employment of vintages until they are fully depreciated. The demand for a vintage turns to zero. However, social transfer schemes offer an outside option for labor before the rental rate of vintage-specific human capital turns to zero. Social transfers, either as general transfers or early retirement schemes may motivate a vintage to exit the production process even before payments for productive work turn to zero. Hence, the supply of labor vintages depends on the level of this transfer as an outside option. In figure $3 \mathrm{~b}$ a simple social transfer is defined as $\theta$. As soon as the transfer level $\theta$ becomes higher than the compensation for productive work of a human capital vintage, $w_{V}(v, t)$, workers of this vintage will switch from productive activity to social transfers. As they are employable only for less than the social transfer level, they will remain without productive employment until they reach the statutory retirement age. Therefore, as long as they officially stay in the labor market they would add to the group of long-term unemployed. If they switch in an early retirement scheme they leave the labor market and retire as not-employable.

(iii) Discarding when a no-skill service sector exists: A further outside option is the existence of an additional sector which does not require any skills or human capital. The no-skill service sector can be regarded as such a sector. In figure $3 \mathrm{c}$ we describe the conditions of such a sector in the most simple way. In this figure we see a technology-using sector employing $m$ vintages and paying wage $w_{V}(v, t)$ for workers with vintage-specific human capital of vintage $v$ at time $t$. If the share of income spend for no-skill services is constant, and labor is assumed to be the only input factor, equilibrium in this sector determines the no-skill wage level that decreases with the number of workers absorbed in this sector. In other words, wages in the service sector increase with the number of vintages which can still be employed in the technology-using sector. This is indicated in figure $3 \mathrm{c}$ by the service sector wage curve $w_{S}(m)$. With $w_{S}(m)$ being an increasing function in $m$, and the reward for vintage-specific human capital $w_{V}(v, t)$ being a downward sloping function of $m$ we can determine the no-skill service sector equilibrium wage $w_{S}^{E}$. As the noskill labor market segment now fully absorbs labor that is not employable in the technology-using sector, unemployment disappears. We obtain a full employment equilibrium at point $E$.

However, the equilibrium service sector wage could be at a very low level. If a society had a minimum wage rate $w^{\text {min }}$, total spending on the service sector would not be sufficient to employ all vintages that leave the technology-using sector. Hence, longterm unemployment would remain. The society has a choice between two options, 
low wages in the no-skill service sector or reasonable payment and unemployment for parts of discarded vintages. Instead of determining the equilibrium no-skill wage (16), we can also assume a minimum wage and determine the resulting unemployment

$$
u=\left(1-\frac{m^{M}}{T}\right)(1-q)=\frac{\frac{c_{S}\left(1-\tau_{1}-\tau_{2}\right)}{\left(1-c_{S}\left(1-\tau_{1}-\tau_{2}\right)\right)} Y}{w_{S}^{\min }}
$$

\section{Biased Technical Change, Internationalization and Economic Retirement}

In this section we look at two major forces which are regarded to have important effects on wage differentials and employability of aging workers and different types of labor. As we suggest a theoretical model to explain the employability of aging workers, the mechanism and effects should be quantitatively relevant. Empirical quantification is extremely difficult when it comes to such an abstract modeling of the production process. Therefore, we link up to a well established empirical literature which addresses a similar phenomenon without focusing on the age structure of the labor force. The effects of skill biased technical change (SBTC) as well as the effects of internationalization on labor wage differentials and employability are broadly studied and quantified. Both elements highly contribute to strong differentials in labor market developments for different skill groups. ${ }^{33}$ As a result we expect that these empirically identified effects are also relevant to the employability of aging workers with different abilities. Thus, in this section we consider biased technical change and internationalization and their potential impact on the labor market conditions of older vintages of workers.

Biased technological change and economic retirement: Like in most growth models, technological progress is the most important variable determining growth. However, in this model technological progress has both growth and employment effects. Due to technological advances new technologies are introduced permanently. Therefore, workers have to adjust their skills permanently. When a technology is scrapped after $m^{*}$ vintages, it is replaced by a new technology. Therefore, the higher the rate of technological progress, i.e., the faster technologies are introduced and old technologies are replaced by new technologies, the faster technologies become outdated. Taking the derivative of (23) gives

$$
\frac{\partial m^{*}}{\partial \hat{\lambda}}<0
$$

\footnotetext{
${ }^{33}$ Katz and Autor (1999), Goldin and Katz (2009) and Acemoglu and Autor (2011) provide excellent surveys of this phenomenon. Furthermore, as argued by Autor et. al. (2003) or Goos et. al (2014) routine biased technical change (RBTC) points towards changes in technical processes that either require technical adaptability or are substituted by automation. The effects of internationalization on different labor market segments are discussed by Wood (1994, 1995, 1998), Rodrik (1997), Slaughter (1998), Feenstra and Hanson (2001), or Harrison and McMillan (2011).
} 
A higher rate of technological progress results in a shorter economic scrapping time $m^{*}{ }^{34}$ Thus, the last $T-m^{*}$ vintages of workers using vintage-specific skills become unemployed. If a technology is discarded, these workers will only be able to use outdated technologies. The reason is the external depreciation of vintage-specific human capital. ${ }^{35}$ Workers entering the labor market are able to use the most modern technology available at that time. However, a fraction of the labor force, namely labor with vintage-specific human capital, is not versatile enough to adjust their skills to newer technologies because the present efforts of lifelong learning are not sufficiently effective for this group. Not only do decreasing earning profiles of older workers occur, in the worst case older workers - belonging to the oldest $T-m^{*}$ technologies - even have to leave the active workforce. These workers are not employable and retire when the productive value of vintage-specific human capital approaches zero. The rate of not-employable labor increases accordingly:

$$
\frac{\partial u}{\partial \hat{\lambda}}=-\frac{(1-q)}{T} \frac{\partial m^{*}}{\partial \hat{\lambda}}>0 .
$$

International integration, outsourcing and economic retirement: In this model increasing global competition leads to a reduction in the relative price of imports $p$. Due to the small country assumption the price of imports is an exogenous variable. Improving terms of trade $(d p<0)$ affects the scrapping time: ${ }^{36}$

$$
\frac{\partial m^{*}}{\partial p}>0
$$

If the price of imports decreases, the demand for imports of intermediate goods will increase overproportionally due to a high elasticity of substitution between domestic inputs and international inputs. I.e., the level of outsourcing of domestic production in favor of international imported intermediate goods and the share of spending on imported goods rises. As a result, the share of spending on domestic labor services and the demand for domestic resources decreases in all vintages. As for installed vintages, flexible labor cannot easily be substituted for vintage-specific human capital. Thus, the spending on both kinds of labor is reduced due to low ex-post substitutability between flexible labor and vintage-specific human capital. Hence, fewer vintages $m^{*}$ can be employed due to reduced spending on domestic labor services. This mechanism suggests that increasing international integration -

\footnotetext{
${ }^{34}$ Theoretically a lower rate of technological progress leads to a later scrapping time. But the restricting $m^{*} \leq T$ has to be considered. If theoretically the model generates a solution $m^{*}>T$ the model has to be solved backward starting with $T=m^{*}$. Using the Kuhn-Tucker conditions it can be shown that in this case the profit maximization condition no longer holds.

${ }^{35}$ According to Neuman and Weiss (1995) we can distinguish between internal and external human capital depreciation. The internal depreciation of human capital - the loss of physical abilities and mental capacities - is not considered in the model.

${ }^{36}$ See Corollary 7.
} 
with decreasing import prices $(d p<0)$ for most of the advanced economies - may also have negative effects on employment opportunities of older workers in OECD countries. According to the model, international specialization and outsourcing can accelerate the speed of endogenous human capital depreciation and may reduce the number of non-employable older workers:

$$
\frac{\partial u}{\partial p}=-\frac{(1-q)}{T} \frac{\partial m^{*}}{\partial p}<0 .
$$

\section{Education Policy}

Up to this point we have discussed how different factors determine the endogenous retirement age from the demand side perspective of the labor market. A complex interaction between input factors and vintage technology determines the demand structure for different qualifications and hence the scrapping time of vintage-specific human capital.

However, in addition to the structure of labor demand the structure of labor supply is also relevant. For a given vintage of people a two-stage education process generates a certain structure of skills and competencies during their working life. For this supply structure of labor, not all labor may be employable until the statutory retirement age (the conditions are discussed above). Although the problem is essentially linked to the production technology used, an important question is whether and how education policy can solve the problem of a (too) rapid endogenous depreciation of vintage-specific human capital. Can it help to align the economic and statutory retirement age of vintage-specific human capital? In other words, how can we adjust the time of full depreciation of human capital vintages to match the politically desired age? Are there policy instruments that may affect the economic retirement age within the introduced two-stage system of education? Can education policy affect the employability of older workers?

[here insert Figure 4: Effects of education policies on employability of vintagespecific human capital. (a) effect of initial schooling, (b) effects of a lifelong learning program and optimal structure of initial schooling and lifelong learning, and (c) effects of education policy on wages in the no-skill sector.]

(i) Education policy in the unrestricted model version: The described problem is caused by the depreciation process of vintage-specific human capital. Skills learned during initial schooling are fully depreciated. Therefore we are able to follow the idea of improving initial schooling and hence the productivity of vintage-specific skills to prolong the usability of these skills. In the model this policy would be an increase in spending on initial schooling.

However, looking at the model's results we can see that raising expenditure on initial schooling does not affect the scrapping time of this sort of human capital and hence 
does not help to align the retirement age with the statutory level. The respective derivative of $(23)$ is

$$
\frac{\partial m^{*}}{\partial \varepsilon_{I}}=0
$$

An improvement in initial schooling fails to reduce older workers' rate of withdrawal from the labor market. While resources spent on initial schooling affect the level of a number of different variables (especially the wage of workers with vintage-specific skills), they do not affect the structure of growth rates that determine scrapping time.

Raising $\varepsilon_{I}$ leads to an increasing supply of vintage-specific human capital such that human capital intensity increases. There are two effects. First, even though scrapping time is not affected, workers with vintage-specific skills achieve higher earnings for the time they are employed. Due to better education, the wage curve of a worker's vintage-specific human capital $w_{V}(v, t)$ (see Figure 4a) moves upward. Second, vintage output and thus aggregate output increases. However, higher spending on initial schooling is neither a feasible policy option for decreasing the duration of non-employment of older workers nor is it able to adjust the economic retirement age:

$$
\frac{\partial u}{\partial \varepsilon_{I}}=0
$$

Since increasing spending on standard initial schooling cannot solve the problem of synchronizing the statutory and the economic retirement age, does higher spending on lifelong learning programs have any effect? Looking again at the model's results we can see that additional spending on lifelong learning programs does not affect the scrapping time either. The respective derivative of (23) is

$$
\frac{\partial m^{*}}{\partial \varepsilon_{I I}}=0
$$

Once again, the structure of the growth rates in the steady state is not affected. How can we explain this unexpected result? In this model there are two explanations. First, all non-vintage-specific factors of production can be flexibly combined with each other and with all vintage technologies. Under perfect competition, decreasing marginal productivity and the no-arbitrage condition in factor markets, all flexible factors allocate to the most productive vintages. After purchasing all flexible factors there is a residual of net revenues that allows for rewarding the vintagespecific (and essential) factor which is human capital. If this residual turns to zero the vintage-specific factor can no longer be rewarded and the vintage is discarded. Therefore, productivity conditions for all flexible factors matter, not the property of the vintage-specific factor. Second, due to a labor service function with an elasticity of substitution equal to one, changes in the structure of labor supply do not affect the shares that are spent on the two factors. Thus, the just mentioned residual of net revenues of each vintage is also not affected; neither is the scrapping time.

However, higher spending on lifelong learning programs may increase the success rate of such programs and hence will help more people acquire the ability to adjust 
to new technologies. Fewer people are expected to be left with vintage-specific skills only. Even if $m^{*}<T$ remains we obtain a decreasing rate of non-employable labor

$$
\frac{\partial u}{\partial \varepsilon_{I I}}=-\left(1-\frac{m}{T}\right) \frac{\partial q}{\partial \varepsilon_{I I}}<0
$$

Therefore, while the problem is not solved it becomes less severe on aggregate. Investments in lifelong learning programs that lead to flexible abilities should therefore complement the introduction of a higher statutory retirement age.

(ii) Education policy under the condition of social transfers: In figure $4 \mathrm{a}$ we can draw the $w_{V}(v, t)$-curve and determine with scrapping rule $w_{V}(v, t)=\theta$ the oldest employed vintage $m^{0}$. We again ask if a higher investment in education $\left(\epsilon_{I}, \varepsilon_{I I}\right)$ can improve the employability of or decrease early retirement among older workers. While we have already derived that $m^{*}$ is not affected a curve representing a higher $\varepsilon_{I}$ or $\varepsilon_{I I}$ may be located below or above the original curve. Determining the partial derivatives (34) and (35) we find positive effects of initial schooling and lifelong learning efforts on the shape of this curve as

$$
\begin{array}{ll}
\frac{d w_{V}(v, t)}{d \varepsilon_{I}(t)}>0, & \frac{\partial^{2} w_{V}(v, t)}{\partial \varepsilon_{I I}^{2}}<0, \\
\frac{d w_{V}(v, t)}{d \varepsilon_{I I}(t)}>0, & \frac{\partial^{2} w_{V}(v, t)}{\partial \varepsilon_{I I}^{2}}<0 .
\end{array}
$$

With a higher expenditure on initial education or lifelong learning, the rental rate of human capital increases and the respective wage curve $w_{V}^{1}(v, t)$ lies above. As a result the wage level $w_{V}$ that fulfils the scrapping rule and provokes an exit from productive activity is reached later (figure 4a,b). More vintages $m^{1}$ can be employed. Hence, in this case lifelong learning schemes have positive effects on effective retirement, labor market participation, and employment. Both kinds of education efforts, initial schooling and lifelong learning schemes have positive but decreasing marginal effects on the upward shift of the earning profile of vintage-specific human capital. As a consequence, it can be expected that an education system with both elements is better than a one-dimensional system. If an economy with only initial schooling is complemented by lifelong learning, the labor market conditions at the end of working life improve.

In addition, for each level of total spending on education we can find a structure of expenditure $\varepsilon_{I} / \varepsilon_{I I}$ that maximizes $w_{V}$ for a steady state at $m^{*}$, see lemma 11 . Thus, there is an efficient structure involving both education efforts that maximizes the effect of education on the employability of older workers. Figure $4 \mathrm{~b}$ indicates such an efficient structure. However, the effects are limited in a way that they would not allow vintages to eventually reach statutory retirement age.

Determining an efficient structure of education efforts with respect to discarding conditions of workers implies a fully informed social planner. While initial schooling often is supplied and enforced by the government, lifelong learning is neither compulsory nor generally regarded as a public responsibility. In our kind of modeling, 
however, education is a public good provided in an optimal structure. Are personal and private decisions to engage in lifelong learning able to establish such an efficient structure? We have some doubts. Sufficient and even more efficient lifelong learning investments would require very well informed and non-myopic, forward-looking labor with a good and clear understanding of the mechanisms. This seems a rather unrealistic assumption. Therefore, it could be argued that the government has a responsibility to establish such a system and set incentives for participation.

(iii) Education policy when a no-skill service sector exists: For this model, variation effects of increasing efforts on lifelong learning are described by figure 4c. In this diagram we again see a new vintage-specific human capital wage curve $w_{V}^{1}(v, t)$ that lies above the original curve. Hence, the switching condition for moving from the technology-using sector to the no-skill service sector is reached later than before at $m^{1}$. This has two positive effects. Older vintages stay longer in the more productive technology sector, and when they switch to the no-skill service sector, equilibrium wages in the no-skill sector become higher $w_{S}^{0}<w_{S}^{1}$. In other words, education can help to raise wages even in sector that does not require any skills.

A wage subsidy could be another helpful policy. If a wage subsidy is paid to labor in the technology-using sector, workers would stay longer in this more productive sector and wages even in the no-skill, low-pay sector would increase. This kind of transfer policy could be an alternative to a minimum wage policy that could potentially conflict with employment goals.

\section{Conclusion}

The employability of an aging population in a world of continuous technical change has become one of the major concerns in today's policy debate. Among others, the European Union in its Lisbon Strategy emphasizes that maintaining employment opportunities even for older workers is crucial for maintaining the EU's competitiveness and social cohesion. At the same time, many governments plan to increase the statutory retirement age in order to stabilize their pension systems. However, in many countries high net withdrawal rates among older workers can be observed.

Our paper intends to explain why the economic - or effective - retirement age may fall short of statutory retirement, leading to the non-employability of older worker cohorts. We argue that the economic retirement age has to be considered endogenous due to the depreciation of vintage-specific human capital. Furthermore, we identify factors that explain a decreasing wage profile and early retirement on the demand side, and examine the effectiveness of policy measures on the supply side. In particular, we analyze whether improvements in the schooling system can synchronize statutory and effective retirement ages or stabilize employment levels in an aging generation.

To analyze the economic determinants of retirement we use a putty-putty vintage model with heterogeneous agents. Schooling is organized in a sequential two-stage 
education system, namely an initial schooling program and a lifelong learning program. Initial schooling equips workers with skills that enable them to use the most recent technology vintage available when a new generation of workers enter the market. Hence initial schooling represents a technology vintage-specific form of training. The subsequent lifelong learning program enables workers to switch to new technologies at any time. Lifelong learning is a resource-absorbing education program that helps to adjust aging labor to a changing technical environment.

The two-stage education system together with differences in workers' learning capabilities generates an endogenous structure of the labor force. Even if all workers participate in lifelong learning, the resources spent on such a program determine the fraction of the labor force that can successfully upgrade skills and hence adapt to new technologies. The fraction of labor that is not successful at the present volume of spending on this program is bound to the technology vintage of its initial schooling period. As shown in the model, upgrading skills and learning to handle new technologies has a strong effect on the income and employability of a population vintage as that vintage ages.

While education is often regarded as the cure for early human capital depreciation, our analysis suggests that the effects of education and even of a lifelong learning program are limited with respect to the duration of employability. The effects, however, depend on the model variation we apply. Three model variations are used to discuss policy implications; namely unrestricted discarding, discarding under the existence of pure social transfers, and discarding under the existence of a no-skill service sector.

More specifically, in the model variation with unrestricted discarding, better initial schooling will affect income levels and the distribution of income but will have no effect on the time path of human capital depreciation and on the economic retirement age. Even a lifelong learning program does not solve the problem of synchronizing the economic and the statutory retirement age. From our model we learn that lifelong learning helps to increase the individual probability of finding a job when workers age and hence improves the employability of an aging generation. However, lifelong learning will not affect the speed of the depreciation process.

In the model variation with given social transfers, we find effects on the duration of productive employment. The expected duration of employment increases with more initial schooling and lifelong learning. An interesting result is that the two forms of education are somehow additive. If an economy with only initial schooling adds a lifelong learning program, the conditions for workers at the end of their working life improve. A system with both elements is better than a one-dimensional system. What is more, there is an optimal structure of such two-dimensional education system. However, the effects are limited in that they would not allow vintages to eventually reach statutory retirement age.

In the model variation with a no-skill service sector, education efforts will improve conditions even if this low-pay sector does not need any skills. There are two positive effects. First, vintages are discarded later and switch later to the low-pay service sector, and second, wages in the no-skill service sector which absorbs discarded 
workers increase.

To summarize, education and in particular lifelong learning programs cannot synchronize the effective and statutory retirement for workers with lower learning capabilities (vintage skills). However, well-designed education programs lead to a smaller fraction of labor that has to leave highly productive activities in the technology-using sector at the end of their working life. Hence well-designed education policies can substitute for simple social transfers or wage subsidies for too-low-wage jobs. 


\section{References}

[1] Acemoglu, D., \& Autor, D. H. (2011), Skills, Tasks and Technologies: Implications for Employment and Earnings. In O. Ashenfelter \& D. E. Card (Eds.), Handbook of Labor Economics, 4B, 1043-1171. Amsterdam: Elsevier B.V.

[2] Autor, D. H., Levy, F., \& Murnane, R. J. (2003), The Skill Content of Recent Technological Change: An Empirical Exploration. The Quarterly Journal of Economics, 118(4), 1279-1333.

[3] Barr, N. (2004), Economics of the Welfare State, 3rd ed., Oxford, Oxford University Press.

[4] Benhabib, J., Rustichini, A. (1993), A Vintage Capital Model of Investment and Growth: Theory and Evidence, in: Becker et al. (eds.), General Equilibrium, Growth and Trade, Academic Press.

[5] Bishop, J. (1991), Achievement, Test Scores, and Relative Wages. In: Kosters, Marvon H. (ed.): Workers and Their Wages: Changing Patterns in the United States. Washington, DC: American Enterprise Institute, 146-86.

[6] Boldrin, M., Dolado, J.J., Jimeno, J.F., Perrachi, F. (1999), The Future of Pensions in Europe, Economic Policy, 32, 7-50.

[7] Boucekkine, R., Licandro, O., Puch, L., del Rio, F. (2005), Vintage capital and the dynamics of the AK model, Journal of Economic Theory, 120, 39-72.

[8] Bouccekkine, R.; Pommeret, A. (2004), Energy saving technical progress and optimal capital stock: The role of embodiment, Economic Modelling, 21, 429444

[9] Boucekkine, R.; De la Croix, D.; Licandro, O. (2002), Vintage human capital, demographic trends, and endogenous growth, Journal of Economic Theory, 104 (2), 340-375

[10] Butrica, Barbara A.; Smith, Karen; Toder, Eric (2002), Projecting poverty rates in 2020 for the 62 and older population: What changes can we expect and why? Center for Retirement Research Working Paper No. 2002-3, Boston College.

[11] Chari, V.V., Hopenhayn, H. (1991), Vintage Human Capital, Growth, and the Diffusion of New Technology, Journal of Political Economy, 99, 1142-65.

[12] Chennells, L., Van Reenen, J. (2002), Technological change and the structure of employment and wages: A survey of the microeconomic evidende. In: Greenan, N.; L'Horty, Y.; Mairess, J. (ed.): Productivity, inequality and the digital economy: a transatlantic perspective. MIT Press, pp. 175-222.

[13] Cremer, H., Pestieau, P. (2003), The Double Dividend of Postponing Retirement, International Tax and Public Finance, 10, 419-434.

[14] De Mello (1995), Overlapping Generations and Complex Dynamics: The Vintage Technology Case, Journal of Macroeconomics, 17, 705-718.

[15] Duval, R. (2003), The Retirement Effects of Old-Age Pension and Early Retirement Schemes in OECD Countries, Department of Economics, OECD, Paris, mimeo. 
[16] EU Commission (2006), Proposal for a Recommendation of the European Parliament and of the Council on the establishment of the European Qualifications Framework for lifelong learning. Commission of the European Community, Brussels, 5.9.2006 COM(2006) 479 final 2006/0163 (COD). http://ec.europa.eu/education/policies/educ/eqf/com_2006_0479_en.pdf

[17] Echevarria, C.A., Iza, A. (2006), Life expectancy, human capital, social security and growth, Journal of Public Economics, 90 (12), 2323-2349

[18] Favreault, Melissa M.; Steuerle, C. Eugene (2008), The Implications of Career Lengths for Social Security. Center for Retirement Research Working Paper No. 2008-5, Boston College.

[19] Feichtinger, G.; Hartl, R.; Kort, P.; Veliov, V. (2006), Anticipation effects of technological progress on., Journal of Economic Theory, 126 (1), 143-164

[20] Fenge, R., Pestieau, P. (2006), Social Security and Early Retirement, Cambridge/MA and London, MIT Press.

[21] Feenstra, R. C., \& Hanson, G. H. (1997), Foreign Direct Investment and Relative Wages: Evidence from Mexico's Maquiladoras. Journal of International Economics, 42(3), 371-393.

[22] Gilchrist, S.; Williams, J. C. (2005), Investment, capacity, and uncertainty A putty clay approach, Review of Economic Dynamics, 8, 1-27

[23] Goetz, R.; Hritonenko, N.; Yatsenko, Y. (2008), The optimal economic lifetime of vintage capital in the, Journal of Economic Dynamics and Control, 32 (9), 3032-3053.

[24] Goldin, C., \& Katz, L (2009), The Race between Education and Technology: The Evolution of U.S. Educational Wage Differentials, 1890 to 2005. NBER Working Paper No. 1298.

[25] Goos, M., Manning, A., \& Salomons, A. (2014), Explaining Job Polarization: Routine-Biased Technological Change and Offshoring. The American Economic Review, 104(8), 2509-26.

[26] Gottschalk, Alfred O. (2006), Dynamics of Economic Well-Being: Spells of Unemployment 2001-2003. Current Population Reports, P70-105, U.S. Census Bureau.

[27] Gould, Eric D. (2002), Rising Wage Inequality, Comparative Advantage, and the Growing Importance of General Skills in the United States. Journal of Labor Economics 20, 105-147.

[28] Grossman, G.M.; Helpman, E. (1991), Innovation and Growth in the Global Economy, Cambridge: MA, MIT Press.

[29] Gruber, J., Wise, D.A. (1999), Social Security and Retirement Around the World, Chicago, Univerity of Chicago Press.

[30] Harrison, A., \& McMillan, M. (2011), Offshoring Jobs? Multinationals and US Manufacturing Employment. Review of Economics and Statistics, 93(3), 857-875.

[31] Holzmann, Robert (2005), Demographic Alternatives for Aging Industrial Countries: Increased Total Fertility Rate, Labor Force Participation, or Immigration. IZA Working Paper No. 1885. 
[32] Hornstein, A.; Krusell, P.; Violante, G. (2007), Technology policy interaction in frictional labour markets, Review of Economic Studies, 74 (4), 1089-1124

[33] Johansen, L. (1959), Substitution Versus Fixed Production Coefficients in the Theory of Economic Growth: A Synthesis, Econometrica, Vol. 27, 157-76.

[34] Johnson, R. (2000), The Effect of Old-Age Insurance on Male Retirement: Evidence from Historical Cross-Country Data, Federal Reserve Bank of Kansas City Working Paper No. 00-09, Kansas City.

[35] Katz, L. F., \& Autor, D. (1999), Changes in the Wage Structure and Earnings Inequality. Handbook of Labor Economics, 3, 1463-1555.

[36] Lazear, E.P. (1979), Why is There Mandatory Retirement? Journal of Political Economy, 87, 1261-1269.

[37] Lazear, E.P. (1981), Agency, Earnings Profiles, and Hours Restrictions, American Economic Review, 71, 606-620.

[38] Lehvari, D.; Weiss, Y. (1974), The effect of risk on the investment in human capital. American Economic Review 64(6), 950-963.

[39] Lucas, R.E. (1988), On the Mechanics of Economic Development, Journal of Monetary Economics, 22, 3-42.

[40] Marchiori, L.(2008), Labour market characteristics and the burden of ageing: North-America versus Europe. Discussion Paper No. 2008-1, Département des Sciences Économiques de l'Université Catholique de Louvain.

[41] Mateos-Planas, X. (2001), Schooling and Distortions in a Vintage Capital Model, Review of Economic Dynamics 4 (1), 127-158.

[42] Meijers, H., Zon, van, A. (1994), RUM: a Recursive Update Putty-Semi-Putty Vintage Production Model: Sectoral Estimation Results for Germany and the Netherlands, MERIT Research Memorandum, 94-010.

[43] Michello, F. A.; Ford, W. F. (2006), The unemployment effects of proposed changes in social security's "Normal Retirement Age". Business Economics XXX, 38-46.

[44] Murnane, R.J., Willett, J.B.; Levy, F. (1995), The Growing Importance of Cognitive Skills in Wage Determination, Review of Economics and Statistics, 77, 251-266.

[45] Nelson, R.R., Phelps, E.S. (1966), Investments in Humans, Technological Diffusion, and Economic Growth, American Economic Review: Papers and Proceedings, 61, 69-75.

[46] Neuman, S., Weiss, A. (1995), On the Effects of Schooling Vintage on Experience-Earnings Profiles: Theory and Evidence, European Economic Review, 39, 943-55.

[47] Nickell, S.; Bell, B. (1996), Changes in the Distribution of Wages and Unemployment in OECD countries, American Economic Review 86 (2), 302-308

[48] OECD (1994), Job Study, OECD, Paris.

[49] OECD (1997), Employment Outlook, OECD: Paris.

[50] OECD (2003), Employment Outlook, OECD: Paris.

[51] OECD (2004), Employment Outlook, OECD: Paris.

[52] OECD (2007), Qualifications and Lifelong Learning. OECD Policy Brief, April 2007, Paris. 
[53] Riphahn, R. T. (1997), Disability Retirement and Unemployment - Substitute Pathways for Labour Force Exit? An Empirical Test for the Case of Germany. Applied Economics, 29 (5), 551-561.

[54] Salter, W.E.G. (1960), Productivity and Technical Change, Cambridge, MA, MIT Press.

[55] Scheper, W. (1968), Recherches récentes sur la Fonction de Production, Économie Mathématique et Économetrie, Namur.

[56] Smeeding, T. M. (1999), Social Security Reform: Improving Benefit Adequacy and Economic Security for Women. Aging Studies Program Policy Brief No. 16/1999, Center for Policy Research, Syracuse.

[57] Smeeding, T. M. (2001), Income maintenance in old age: What can be learned from cross-national comparisons? Luxembourg Income Study Working Paper No. 263.

[58] Slaughter, M. (1998), International trade and labour-market outcomes: Results, questions, and policy options. The Economic Journal, 108(450), 1452-1462.

[59] Solow, R.M. (1960), Investment and Technical Progress, in: Arrow, K., Karlin, S., Suppes, P. (eds.), Mathematical Methods in the Social Sciences 1959, Stanford, 89-104.

[60] Stephens, K.J. (1971), A Growth Model with Capital and Labour Vintages, Metroeconomica, 23, 103-18.

[61] Taber, C. (2001), The Rising College Premium in the Eighties: Return to College or Return to Unobserved Ability. Review of Economic Studies 68, 66569.

[62] Van Hilten, O. (1991), The Optimal Lifetime of Capital Equipment, Journal of Economic Theory, 55, 449-454.

[63] Van Imhoff, E. (1988), Age Structure, Education, and the Transition of Technical Change, Journal of Population Economics, 1, 167-81.

[64] Violante, G. (2002), Technological acceleration, skill transferability and the rise of residual inequality, Quarterly Journal of Economics, 117 (1), 297-338

[65] Weinberg, B. A. (2000), Computer Use and the Demand for Female Workers. Industrial and Labor Relations Review 53, 290-308.

[66] Welch, F. (1970), Education in production. Journal of Political Economy 78, 35-59.

[67] Wood, A. (1995), How Trade Hurt Unskilled Workers. The Journal of Economic Perspectives, 9(3), 57-80.

[68] Wood, A. (1997), Openness and Wage Inequality in Developing Countries: the Latin American Challenge to East Asian Conventional Wisdom. The World Bank Economic Review, 11(1), 33-57.

[69] Wood, A. (1998), Globalisation and the Rise in Labour Market Inequalities. The Economic Journal, 108(450), 1463-1482.

[70] Zon, van, A. (1994), RUM: a Simple Recursive Update Model Providing a Condensed Representation of a Putty-Semi-Putty Vintage Model, MERIT Research Memorandum, 94-002. 


\section{Appendix}

In the appendix we show that we can solve for a stationary vector of variables and in particular determine a stationary scrapping time.

First, we rewrite all variables in intensity form as suggested in section 3. Second, we need to show that vintage coefficients $\alpha_{v}, \beta_{v}, \delta_{v}$, and $\gamma_{v}$ can take stationary values: Hence, using "^" notation as $\hat{x}=\frac{d \ln (x(t))}{d t}=\frac{\dot{x}}{x}$ coefficients are stationary if $\hat{\alpha}_{v}=\hat{\beta}_{v}=\hat{\delta}_{v}=\hat{\gamma}_{v}=0$ this is shown in Lemma 1. Lemma 2 determines optimal and stationary relations between input factors and output ex ante and ex post. Lemma 2 is needed to solve for optimal input choices. E.g. in order to determine the demand for adaptable labor (24) we use equation (21) and Lemma 2 [footnote 23] Further, in Corollary 3 we show that wage of flexible labor is proportional to vintage income in intensity form in time of installation. For all installed vintages Corollary 4 shows that vintage output in intensity form is proportional to the wages of flexible labor and is only driven by the exogenous rate of technical change. The same holds for imports in intensity form. Corollary 5 shows that at time of installation and after installation, optimality conditions for imports hold. That is, the import price equals marginal productivity and there is a smooth adjustment between installed vintages and new vintages at time of installation (no jumps). Using Lemma 1 and 2 as well as Corollaries 3 to 5 and the assumption that $\hat{\lambda}:=$ const for all vintages we can determine a steady state value for $m(t)=m^{*}$. This is done in Theorem 6 . Corollary 7 takes the derivatives of $m$ and vintage-specific wages with respect to some variables of interest. To complete, in Lemma 8 we derive the aggregate output over all vintages, $Y$ or $y=\frac{Y}{N_{I I}^{d}}$, and show that both grow at the rate of technological progress in steady-state. Lemma 9 shows that condition in Theorem 6 generally holds for low substitutability of the different kinds of labor ex post. It also derives some intermediary results which we use later. In Theorem 10 we determine the quasi rent of human capital and restrictions.

Lemma 1 In steady-state it is $\hat{\alpha}_{v}=\hat{\beta}_{v}=\hat{\delta}_{v}=\hat{\gamma}_{v}=0$. 
Proof: Equation (8) is equivalent to

$$
\begin{gathered}
(1-\gamma)\left(\frac{Y(t, t)}{S(t, t)}\right)^{\rho_{1}}=\delta_{t}\left(\frac{Y(t, t)}{S(t, t)}\right)^{\rho_{2}} \\
\Longleftrightarrow \quad \delta_{t}=(1-\gamma)\left(\frac{Y(t, t)}{S(t, t)}\right)^{\rho_{1}-\rho_{2}} .
\end{gathered}
$$

It follows directly that $\hat{\delta}_{t}=0$. Using condition (9) leads to

$$
\begin{aligned}
& Y(t, t)^{-\rho_{2}}=\gamma_{t} \operatorname{Im}(t, t)^{-\rho_{2}}+\delta_{t} S(t, t)^{-\rho_{2}} \\
\Longleftrightarrow & \gamma_{t}=\frac{Y(t, t)^{-\rho_{2}}-\delta_{t} S(t, t)^{-\rho_{2}}}{\operatorname{Im}(t, t)^{-\rho_{2}}}
\end{aligned}
$$

and it follows $\hat{\gamma}_{t}=0$. Equation (12) can be transformed to

$$
\begin{gathered}
\alpha=\alpha_{t} \lambda(t, t)^{-\rho_{4}}\left(\frac{S(t, t)}{N_{I I}^{d}(t, t)}\right)^{\rho_{4}} \\
\Longleftrightarrow \quad \alpha_{t}=\alpha \lambda(t, t)^{\rho_{4}}\left(\frac{S(t, t)}{N_{I I}^{d}(t, t)}\right)^{-\rho_{4}} .
\end{gathered}
$$

The last equation implies $\hat{\alpha}_{t}=0$. Using condition (13) leads to

$$
\begin{gathered}
S(t, t)^{-\rho_{4}}=\alpha_{t} \Lambda(t, t)^{-\rho_{4}}+\beta_{t} H(t, t)^{-\rho_{4}} \\
\Longleftrightarrow \quad \beta_{t}=\frac{S(t, t)^{-\rho_{4}}-\alpha_{t} \Lambda(t, t)^{-\rho_{4}}}{H(t, t)^{-\rho_{4}}}
\end{gathered}
$$

and it follows that $\hat{\beta}_{t}=0$.

Lemma 2 If for the time of installing a new technology condition (19) holds, it will be $i m(t, t)=y(t, t)\left(\frac{\gamma}{p}\right)^{\frac{1}{1+\rho_{1}}}$ and

$$
y(t, t)=c_{1} s(t, t) \quad \text { with } \quad c_{1}:=(1-\gamma)^{-\frac{1}{\rho_{1}}}\left(1-\gamma^{\frac{1}{1+\rho_{1}}} p^{\frac{\rho_{1}}{1+\rho_{1}}}\right)^{\frac{1}{\rho_{1}}}
$$

As for an installed technology equation (20) holds, it follows $i m(v, t)=y(v, t)\left(\frac{\gamma_{v}}{p}\right)^{\frac{1}{1+\rho_{2}}}$ and

$$
y(v, t)=c_{2} s(v, t) \quad \text { with } \quad c_{2}:=\left(\delta_{v}\right)^{-\frac{1}{\rho_{2}}}\left(1-\gamma_{v}^{\frac{1}{1+\rho_{2}}} p^{\frac{\rho_{2}}{1+\rho_{2}}}\right)^{\frac{1}{\rho_{2}}} .
$$

Proof: It is

$$
\frac{\partial y(t, t)}{\partial i m(t, t)}=p \quad \Longleftrightarrow \quad y(t, t)=i m(t, t)\left(\frac{p}{\gamma}\right)^{\frac{1}{1+\rho_{1}}} \quad \Longleftrightarrow \quad i m(t, t)=y(t, t)\left(\frac{\gamma}{p}\right)^{\frac{1}{1+\rho_{1}}} .
$$


Using (6) written in intensity form and rearranging provides

$$
\begin{aligned}
y(t, t) & =\left(\gamma \operatorname{im}(t, t)^{-\rho_{1}}+(1-\gamma) s(t, t)^{-\rho_{1}}\right)^{-\frac{1}{\rho_{1}}} \\
\frac{y(t, t)}{s(t, t)} & =\left(\gamma\left(\frac{i m(t, t)}{s(t, t)}\right)^{-\rho_{1}}+(1-\gamma)\right)^{-\frac{1}{\rho_{1}}} \\
\left(\frac{y(t, t)}{s(t, t)}\right)^{-\rho} & =\gamma\left(\frac{i m(t, t)}{s(t, t)}\right)^{-\rho_{1}}+(1-\gamma)
\end{aligned}
$$

Plug-in from above $i m(t, t)=y(t, t)\left(\frac{\gamma}{p}\right)^{\frac{1}{1+\rho_{1}}}$

$$
\begin{aligned}
& \left(\frac{y(t, t)}{s(t, t)}\right)^{-\rho_{1}}=\gamma^{\frac{1}{1+\rho_{1}}} p^{\frac{\rho_{1}}{1+\rho_{1}}}\left(\frac{y(t, t)}{s(t, t)}\right)^{-\rho_{1}}+(1-\gamma) \\
\Longleftrightarrow & \left(\frac{y(t, t)}{s(t, t)}\right)^{-\rho_{1}}=\frac{1-\gamma}{1-\gamma^{\frac{1}{1+\rho_{1}}} p^{\frac{\rho_{1}}{1+\rho_{1}}}} \\
\Longleftrightarrow & y(t, t)=s(t, t)(1-\gamma)^{-\frac{1}{\rho_{1}}}\left(1-\gamma^{\frac{1}{1+\rho_{1}}} p^{\frac{\rho_{1}}{1+\rho_{1}}}\right)^{\frac{1}{\rho_{1}}} .
\end{aligned}
$$

There is a linear relation between $i m(t, t)$ and $s(t, t)$ :

$$
\begin{gathered}
i m(t, t)\left(\frac{p}{\gamma}\right)^{\frac{1}{1+\rho_{1}}}=s(t, t)(1-\gamma)^{-\frac{1}{\rho_{1}}}\left(1-\gamma^{\frac{1}{1+\rho_{1}}} p^{\frac{\rho_{1}}{1+\rho_{1}}}\right)^{\frac{1}{\rho_{1}}} \\
\Longleftrightarrow \quad i m(t, t)=s(t, t)(1-\gamma)^{-\frac{1}{\rho_{1}}}\left(1-\gamma^{\frac{1}{1+\rho_{1}}} p^{\frac{\rho_{1}}{1+\rho_{1}}}\right)\left(\frac{\gamma}{p}\right)^{\frac{1}{1+\rho_{1}}} .
\end{gathered}
$$

The first statement of the lemma follows, if this result is inserted in the production function:

$$
\begin{aligned}
y(t, t) & =\left(\gamma\left[\left(\frac{1-\gamma}{1-\gamma^{\frac{1}{1+\rho_{1}}} p^{\frac{\rho_{1}}{1+\rho_{1}}}}\right)^{-\frac{1}{\rho_{1}}}\left(\frac{\gamma}{p}\right)^{\frac{1}{1+\rho_{1}}}\right]^{-\rho_{1}}+(1-\gamma)\right)^{-\frac{1}{\rho_{1}}} s(t, t) \\
& =\left(\left(\frac{1-\gamma}{1-\gamma^{\frac{1}{1+\rho_{1}}} p^{\frac{\rho_{1}}{1+\rho_{1}}}}\right) \gamma^{\frac{1}{1+\rho_{1}}} p^{\frac{\rho_{1}}{1+\rho_{1}}}+(1-\gamma)\right)^{-\frac{1}{\rho_{1}}} s(t, t) \\
& =\underbrace{\left(\frac{1-\gamma}{1-\gamma^{\frac{1}{1+\rho_{1}}} p^{\frac{\rho_{1}}{1+\rho_{1}}}}\right)^{-\frac{1}{\rho_{1}}}}_{=: c_{1}} s(t, t) .
\end{aligned}
$$

The second part of the proof is organized in the same way. It is

$$
\frac{\partial y(v, t)}{\partial i m(v, t)}=p \quad \Longleftrightarrow \quad y(v, t)=i m(v, t)\left(\frac{p}{\gamma_{v}}\right)^{\frac{1}{1+\rho_{2}}} \quad \Longleftrightarrow \quad i m(v, t)=y(v, t)\left(\frac{\gamma_{v}}{p}\right)^{\frac{1}{1+\rho_{2}}} .
$$


It follows that

$$
\begin{aligned}
& \left(\frac{y(v, t)}{s(v, t)}\right)^{-\rho_{2}}=\gamma_{v}\left(\frac{i m(v, t)}{s(v, t)}\right)^{-\rho_{2}}+\delta_{v}=\gamma_{v}^{\frac{1}{1+\rho_{2}}} p^{\frac{\rho_{2}}{1+\rho_{2}}}\left(\frac{y(v, t)}{s(v, t)}\right)^{-\rho_{2}}+\delta_{v} \\
\Longleftrightarrow & \left(\frac{y(v, t)}{s(v, t)}\right)^{-\rho_{2}}=\frac{\delta_{v}}{1-\gamma_{v}^{\frac{1}{1+\rho_{2}}} p^{\frac{\rho_{2}}{1+\rho_{2}}}} \\
\Longleftrightarrow & y(v, t)=s(v, t)\left(\frac{\delta_{v}}{1-\gamma_{v}^{\frac{1}{1+\rho_{2}}} p^{\frac{\rho_{2}}{1+\rho_{2}}}}\right)^{-\frac{1}{\rho_{2}}} .
\end{aligned}
$$

As above we obtain for $i m(v, t)$ and $s(v, t)$ :

$$
\begin{gathered}
i m(v, t)\left(\frac{p}{\gamma_{v}}\right)^{\frac{1}{1+\rho_{2}}}=s(v, t)\left(\frac{\delta_{v}}{1-\gamma_{v}^{\frac{1}{1+\rho_{2}}} p^{\frac{\rho_{2}}{1+\rho_{2}}}}\right)^{-\frac{1}{\rho_{2}}} \\
\Longleftrightarrow \quad i m(v, t)=s(v, t)\left(\frac{\delta_{v}}{1-\gamma_{v}^{\frac{1}{1+\rho_{2}}} p^{\frac{\rho_{2}}{1+\rho_{2}}}}\right)^{-\frac{1}{\rho_{2}}}\left(\frac{\gamma_{v}}{p}\right)^{\frac{1}{1+\rho_{2}}} .
\end{gathered}
$$

Inserting this result into the production function (7), the second statement follows:

$$
\begin{aligned}
y(v, t) & =\left(\gamma_{v}\left[\left(\frac{\delta_{v}}{1-\gamma_{v}^{\frac{1}{1+\rho_{2}}} p^{\frac{\rho_{2}}{1+\rho_{2}}}}\right)^{-\frac{1}{\rho_{2}}}\left(\frac{\gamma_{v}}{p}\right)^{\frac{1}{1+\rho_{2}}}\right]^{-\rho_{2}}+\delta_{v}\right)^{-\frac{1}{\rho_{2}}} s(v, t) \\
& =\left(\left(\frac{\delta_{v}}{1-\gamma_{v}^{\frac{1}{1+\rho_{2}}} p^{\frac{\rho_{2}}{1+\rho_{2}}}}\right) \gamma_{v}^{\frac{1}{1+\rho_{2}}} p^{\frac{\rho_{2}}{1+\rho_{2}}}+\delta_{v}\right)^{-\frac{1}{\rho_{2}}} s(v, t) \\
& =\underbrace{\left(\frac{\delta_{v}}{1-\gamma_{v}^{\frac{1}{1+\rho_{2}}} p^{\frac{\rho_{2}}{1+\rho_{2}}}}\right)^{-\frac{1}{\rho_{2}}}}_{=: c_{2}} s(v, t) .
\end{aligned}
$$

Observe that $c_{2}$ is constant, because $\gamma_{v}$ and $\delta_{v}$ are constant due to Lemma 1 .

Corollary 3 For the wage rate of flexible labor the following condition holds: $w(t)=$ $\alpha y(t, t)$

Proof: Using Lemma 2 we obtain the wage when writing equation (21) for $v=t$ :

$$
\begin{aligned}
w(t) & =\frac{\partial Y(t, t)}{\partial N_{I I}^{d}(t, t)}=\frac{\partial Y(t, t)}{\partial S(t, t)} \frac{\partial S(t, t)}{\partial N_{I I}^{d}(t, t)} \\
& =c_{1} \frac{\partial S(t, t)}{\partial N_{I I}^{d}(t, t)}=c_{1} \alpha \frac{S(t, t)}{N_{I I}^{d}(t, t)}=\alpha y(t, t) .
\end{aligned}
$$


Corollary 4 For the output in intensity form we obtain

$$
y(v, t)=c_{2}\left(\frac{w(t)}{c_{2} \alpha_{v} \lambda(v, t)^{-\rho_{4}}}\right)^{\frac{1}{1+\rho_{4}}}
$$

and therefore

$$
y(v, t)=y(0,0) e^{\frac{1}{1+\rho_{4}} \hat{\lambda} t} e^{\frac{\rho_{4}}{1+\rho_{4}} \hat{\lambda} v} .
$$

For the imports it is

$$
i m(v, t)=i m(0,0) e^{\frac{1}{1+\rho_{4}} \hat{\lambda} t} e^{\frac{\rho_{4}}{1+\rho_{4}} \hat{\lambda} v}
$$

Proof: Using Lemma 2 equation (21) for $v<t$ and $\hat{\lambda}=$ const. leads to:

$$
\begin{aligned}
w(t) & =\frac{\partial Y(v, t)}{\partial N_{I I}^{d}(v, t)}=\frac{\partial Y(v, t)}{\partial S(v, t)} \frac{\partial S(v, t)}{\partial N_{I I}^{d}(v, t)} \\
& =c_{2} \frac{\partial S(v, t)}{\partial N_{I I}^{d}(v, t)}=c_{2} \alpha_{v} \lambda(v, t)^{-\rho_{4}}\left(\alpha_{v} \lambda(v, t)^{-\rho_{4}}+\beta_{v} \kappa(v, t)^{-\rho_{4}}\right)^{-\frac{1+\rho_{4}}{\rho_{4}}} \\
\Longleftrightarrow \quad \kappa(v, t)^{-\rho_{4}} & =\frac{\left(\frac{w(t)}{c_{2} \alpha_{v} \lambda(v, t)^{-\rho_{4}}}\right)^{-\frac{\rho_{4}}{1+\rho_{4}}}-\alpha_{v} \lambda(v, t)^{-\rho_{4}}}{\beta_{v}} .
\end{aligned}
$$

Inserting this result into the production function (11) and using Lemma 2 we obtain

$$
y(v, t)=c_{2}\left(\frac{w(t)}{c_{2} \alpha_{v} \lambda(v, t)^{-\rho_{4}}}\right)^{\frac{1}{1+\rho_{4}}} .
$$

The growth rate of $y(v, t)$ follows from $\hat{w}=\hat{\lambda}$ and $\hat{\alpha}=0$ by Lemma 1 and Corollary 3 under staionary conditions. The statement for the imports follows from Lemma 2, since $i m(v, t)=c_{3} y(v, t)$ with $c_{3}=\left(\frac{\gamma_{v}}{p}\right)^{\frac{1}{1+\rho_{2}}}$ holds.

Corollary 5 Equation (20) for $v=t$ is equivalent to equation (19), i.e. it is $\frac{\partial y(t, t)}{\partial i m(t, t)}=p$.

Proof: The statement follows directly, if $y(t, v)=y(t, t) e^{-\frac{1}{1+\rho_{4}}}$ and $i m(t, v)=$ $i m(t, t) e^{-\frac{1}{1+\rho_{4}}}$ are inserted in equation (19). It has to be considered that only the second part of Lemma 2 is used.

Theorem 6 The scrapping time in steady-state is

$$
m^{*}=\frac{\ln \left[\left(1-\left(\frac{\gamma}{p}\right)^{\frac{1}{1+\rho_{1}}}\right)^{-1} \alpha\right]}{-\hat{\lambda}} \frac{1+\rho_{4}}{\rho_{4}} .
$$


Proof: A vintage is discarded, if returns of the vintage-specific human capital are zero:

Corollary 4 shows how the income of different vintages are related to each other. $y(v, t)$ is $y(v, t)=y(0,0) e^{\frac{1}{1+\rho_{4}} \hat{\lambda} t} e^{\frac{\rho_{4}}{1+\rho_{4}} \hat{\lambda} v}$. We now look at the vintage $t-m$ and obtain $y(t-m, t)=y(0,0) e^{\frac{1}{1+\rho_{4}} \hat{\lambda} t} e^{\frac{\rho_{4}}{1+\rho_{4}} \hat{\lambda}(t-m)}$ and $y(t, t)=y(0,0) e^{\frac{1}{1+\rho_{4}} \hat{\lambda} t} e^{\frac{\rho_{4}}{1+\rho_{4}} \hat{\lambda} t}$, hence dividing $y(t-m, t)$ by $y(t, t)$ and rearanging gives $y(t-m, t)=y(t, t) e^{-\frac{\rho_{4}}{1+\rho_{4}} \hat{\lambda} m}$. Following Lemma 2 and Corollary 4 accoordingly we obtain $i m(t-m, t)=i m(t, t) e^{-\frac{\rho_{4}}{1+\rho_{4}} \hat{\lambda} m}=$ $y(t, t)\left(\frac{\gamma}{p}\right)^{\frac{1}{1+\rho_{1}}} e^{-\frac{\rho_{4}}{1+\rho_{4}} \hat{\lambda} m}$ and following Corollary 3 it is $w(t)=\alpha y(t, t)$. Eliminating $y(t, t)$, we obtain:

$$
\begin{gathered}
e^{-\frac{\rho_{4}}{1+\rho_{4}} \hat{\lambda} m^{*}}\left(1-\left(\frac{\gamma}{p}\right)^{\frac{1}{1+\rho_{1}}}\right)=\alpha \\
\Longleftrightarrow \quad-\frac{\rho_{4}}{1+\rho_{4}} \hat{\lambda} m^{*}=\ln \alpha-\ln \left(1-\left(\frac{\gamma}{p}\right)^{\frac{1}{1+\rho_{1}}}\right) \\
\Longleftrightarrow \quad m^{*}=-\frac{\ln \alpha-\ln \left(1-\left(\frac{\gamma}{p}\right)^{\frac{1}{1+\rho_{1}}}\right)}{\hat{\lambda}} \frac{1+\rho_{4}}{\rho_{4}} .
\end{gathered}
$$

Note, that from Lemma 8 and the conditions stated (including $p>\gamma>0$ ) we will obtain $\ln \alpha-\ln \left(1-\left(\frac{\gamma}{p}\right)^{\frac{1}{1+\rho_{1}}}\right)<0$ for $N_{I I}^{d}(t, v)=0$, which happens in the moment of being discarded. $\rho_{4}$ is positive as we assume above low ex post substitutability $\sigma_{4}:=\frac{1}{1+\rho_{4}}<\sigma_{3}=1$ for adaptable labor and vintage-specific human capital see (11).

Corollary 7 In steady-state it is:

$$
\frac{\partial m^{*}}{\partial \hat{\lambda}}<0, \quad \frac{\partial m^{*}}{\partial p}>0, \quad \frac{\partial w_{V}(v, t)}{\partial \varepsilon_{I}(t)}>0, \quad \frac{\partial w_{V}(v, t)}{\partial \varepsilon_{I I}(t)}>0 .
$$

Proof: Using the conditions stated in Theorem (6) we obtain the derivatives of $m^{*}$

$$
\begin{aligned}
\frac{\partial m^{*}}{\partial \hat{\lambda}} & =\frac{\ln \left[\left(1-\left(\frac{\gamma}{p}\right)^{\frac{1}{1+\rho_{1}}}\right)^{-1} \alpha\right]}{\hat{\lambda}} \frac{1+\rho_{4}}{\rho_{4}} \frac{1}{\hat{\lambda}}=-\frac{m^{*}}{\hat{\lambda}}<0 \\
\frac{\partial m^{*}}{\partial p} & =\frac{1}{\hat{\lambda}} \frac{1+\rho_{4}}{\rho_{4}} \frac{1}{\left(1-\left(\frac{\gamma}{p}\right)^{\frac{1}{1+\rho_{1}}}\right)^{-1}}\left(\frac{1}{1+\rho_{1}}\right)\left(\frac{\gamma}{p}\right)^{\frac{1}{1+\rho_{1}}} \frac{1}{p}>0
\end{aligned}
$$


Further, for the proof of the third and fourth inequality we take the zero profit condition in intensity form. We know for vintage $t-m$ just before being discarded

$$
y(t-m, t)-i m(t-m, t)-w(t)=w_{V}(t-m, t) \frac{N_{I}(t-m, t)}{N_{I I}^{d}(t, t)} .
$$

substituting for $y\left(t-m^{*}, t\right)=y(t, t) e^{-\frac{\rho_{4}}{1+\rho_{4}} \hat{\lambda} m}$ (see proof of Theorem 6), for $i m(t-$ $\left.m^{*}, t\right)=y(t, t)\left(\frac{\gamma}{p}\right)^{\frac{1}{1+\rho_{1}}} e^{-\frac{\rho_{4}}{1+\rho_{4}} \hat{\lambda} m}$, for $w(t)=\alpha y(t, t)$ (see Corollary 3 ) we obtain

$$
\begin{aligned}
y(t, t) e^{-\frac{\rho_{4}}{1+\rho_{4}} \hat{\lambda} m}-y(t, t)\left(\frac{\gamma}{p}\right)^{\frac{1}{1+\rho_{1}}} e^{-\frac{\rho_{4}}{1+\rho_{4}} \hat{\lambda} m}-\alpha y(t, t)=w_{V}(t-m(t), t) \frac{N_{I}(t-m, t)}{N_{I I}^{d}(t, t)} \\
{\left[e^{-\frac{\rho_{4}}{1+\rho_{4}} \hat{\lambda} m}\left(1-\left(\frac{\gamma}{p}\right)^{\frac{1}{1+\rho_{1}}}\right)-\alpha\right] y(t, t)=w_{V}(t-m(t), t) \frac{(1-q) N^{s}(t-m, t)}{N_{I I}^{d}(t, t)} . }
\end{aligned}
$$

Rearanging and making use of $q$ to be constant in steady state for a given share $\varepsilon_{I I}$ provides

$$
\begin{aligned}
w_{V}(t-m(t), t) & =\left[e^{-\frac{\rho_{4}}{1+\rho_{4}} \hat{\lambda} m}\left(1-\left(\frac{\gamma}{p}\right)^{\frac{1}{1+\rho_{1}}}\right)-\alpha\right] y(t, t) \frac{N_{I I}^{d}(t, t)}{(1-q) N^{s}(v, t)} \\
& =\left[e^{-\frac{\rho_{4}}{1+\rho_{4}} \hat{\lambda} m}\left(1-\left(\frac{\gamma}{p}\right)^{\frac{1}{1+\rho_{1}}}\right)-\alpha\right] c_{1} s(t, t)\left(\frac{N_{I I}^{d}(t, t)}{(1-q) N^{s}(v, t)}\right)
\end{aligned}
$$

where according to Lemma $2, y(t, t)=c_{1} s(t, t)$.Using $s(t, t)=\frac{S(t, t)}{N_{I I}^{d}(t, t)}=\left(\frac{h(t, t) N_{I}(t, t)}{N_{I I}^{d}(t, t)}\right)^{1-\alpha} \lambda(t, t)^{\alpha}$ and defining $c_{4}:=\left[e^{-\frac{\rho_{4}}{1+\rho_{4}} \hat{\lambda} m}\left(1-\left(\frac{\gamma}{p}\right)^{\frac{1}{1+\rho_{1}}}\right)-\alpha\right] c_{1}[\lambda(t, t)]^{\alpha}$ we obtain the vintagespecific wages as

$$
\begin{aligned}
w_{V}(t-m(t), t)= & c_{4}\left(\frac{\varepsilon_{I} Y(t)}{N^{s}(t, t)} \frac{\left(1-q\left(\varepsilon_{I I}\right)\right) N^{s}(t, t)}{N_{I I}^{d}(t, t)}\right)^{1-\alpha}\left(\frac{N_{I I}^{d}(t, t)}{\left(1-q\left(\varepsilon_{I I}\right)\right) N^{s}(t, t)}\right) \\
= & c_{4}\left(\frac{\varepsilon_{I} Y(t)}{N^{s}(t, t)} \frac{\left(1-q\left(\varepsilon_{I I}\right)\right) N^{s}(t, t)}{N_{I I}^{d}(t, t)}\right)^{-\alpha} \\
& \frac{\varepsilon_{I} Y(t)}{N^{s}(t, t)} \frac{\left(1-q\left(\varepsilon_{I I}\right)\right) N^{s}(t, t)}{N_{I I}^{d}(t, t)} \frac{N_{I I}^{d}(t, t)}{\left(1-q\left(\varepsilon_{I I}\right)\right) N^{s}(t, t)}
\end{aligned}
$$


and the derivative of $w_{V}(t-m(t), t)$ with respect to $\varepsilon_{I}$ is

$$
\begin{aligned}
\frac{d w_{V}}{d \varepsilon_{I}}= & (1-\alpha) c_{4}\left(\frac{\varepsilon_{I} Y(t)}{N^{s}(t, t)} \frac{\left(1-q\left(\varepsilon_{I I}\right)\right) N^{s}(t, t)}{N_{I I}^{d}(t, t)}\right)^{-\alpha} \\
& \frac{N_{I I}^{d}(t, t)}{\left(1-q\left(\varepsilon_{I I}\right)\right) N^{s}(t, t)} \frac{\left(1-q\left(\varepsilon_{I I}\right)\right) N^{s}(t, t)}{N_{I I}^{d}(t, t)} \frac{Y(t)}{N^{s}(t, t)} \\
= & (1-\alpha) c_{4}\left(\frac{\varepsilon_{I} Y(t)}{N^{s}(t, t)} \frac{\left(1-q\left(\varepsilon_{I I}\right)\right) N^{s}(t, t)}{N_{I I}^{d}(t, t)}\right)^{-\alpha} \frac{Y(t)}{N^{s}(t, t)}>0 .
\end{aligned}
$$

In order to take the derivative with respect to $\varepsilon_{I I}$ we can simplify the calculations by rearranging $w_{V}(t-m(t), t)$ before taking the derivative. $w_{V}(t-m(t), t)$ can be also rewritten as

$$
w_{V}(t-m(t), t)=c_{4}\left(\frac{\varepsilon_{I} Y(t)}{N^{s}(t, t)} \frac{\left(1-q\left(\varepsilon_{I I}\right)\right) N^{s}(t, t)}{N_{I I}^{d}(t, t)}\right)^{-\alpha} \frac{\varepsilon_{I} Y(t)}{N^{s}(t, t)} .
$$

Then, the derivative with respect to $\varepsilon_{I I}$ is

$$
\begin{gathered}
\frac{d w_{V}}{d \varepsilon_{I I}}=-\alpha c_{4}\left(\frac{\varepsilon_{I} Y(t)}{N^{s}(t, t)} \frac{\left(1-q\left(\varepsilon_{I I}\right)\right) N^{s}(t, t)}{N_{I I}^{d}(t, t)}\right)^{-\alpha-1} \\
\left(\frac{\varepsilon_{I} Y(t)}{N^{s}(t, t)}\right)^{2} \frac{\left(-q^{\prime}\left(\varepsilon_{I I}\right)\right) N^{s}(t, t)}{N_{I I}^{d}(t, t)} \\
\frac{d w_{V}}{d \varepsilon_{I I}}=\alpha c_{4}\left(\frac{\varepsilon_{I} Y(t)}{N^{s}(t, t)} \frac{\left(1-q\left(\varepsilon_{I I}\right)\right) N^{s}(t, t)}{N_{I I}^{d}(t, t)}\right)^{-\alpha-1}\left(\frac{\varepsilon_{I} Y(t)}{N^{s}(t, t)}\right)^{2} \frac{1}{N_{I I}^{d}(t, t)} \frac{Y(t)}{\lambda(t, t)}>0
\end{gathered}
$$

Lemma 8 It is $N_{I I}^{d}\left(t, t+m^{*}\right)>0$ and $Y\left(t, t+m^{*}\right)>0$.

Proof: It is $\alpha_{v} \lambda(t, t)^{-\rho_{4}}=\alpha\left(\frac{y(t, t)}{c_{2}}\right)^{-\rho_{4}}$ and $y(v, v)=y(t, t) e^{\hat{\lambda}(v-t)}$. Using these conditions we obtain

$$
\begin{aligned}
\frac{N_{I I}^{d}(t, v)}{N_{I I}^{d}(t, t)} & =\left(\frac{\left(\frac{w(v)}{c_{2} \alpha_{t} \lambda(t, t)^{-\rho_{4}}}\right)^{-\frac{\rho_{4}}{1+\rho_{4}}}-\alpha_{t} \lambda(t, t)^{-\rho_{4}}}{\left(\frac{w(t)}{c_{2} \alpha_{t} \lambda(t, t)^{-\rho_{4}}}\right)^{-\frac{\rho_{4}}{1+\rho_{4}}}-\alpha_{t} \lambda(t, t)^{-\rho_{4}}}\right)^{\frac{1}{\rho_{4}}} \\
& =\left(\frac{c_{2}^{\rho_{4}} y(t, t)^{-\rho_{4}} e^{-\hat{\lambda}(v-t) \frac{\rho_{4}}{1+\rho_{4}}}-\alpha y(t, t)^{-\rho_{4}} c_{2}^{\rho_{4}}}{c_{2}^{\rho_{4}} y(t, t)^{-\rho_{4}}-\alpha y(t, t)^{-\rho_{4}} c_{2}^{\rho_{4}}}\right)^{\frac{1}{\rho_{4}}} \\
& =\left(\frac{e^{-\hat{\lambda}(v-t) \frac{\rho_{4}}{1+\rho_{4}}}-\alpha}{1-\alpha}\right)^{\frac{1}{\rho_{4}}} .
\end{aligned}
$$


It follows that

$$
\begin{aligned}
N_{I I}^{d}(t, v)=0 \quad & \Longleftrightarrow \quad v-t=\frac{\ln \alpha}{-\hat{\lambda}} \frac{1+\rho_{4}}{\rho_{4}}>m^{*} \\
& \Longleftrightarrow \quad \ln \alpha<\ln \left[\left(1-\left(\frac{\gamma}{p}\right)^{\frac{1}{1+\rho_{1}}}\right)^{-1} \alpha\right] \\
& \Longleftrightarrow \quad 1<\left(1-\left(\frac{\gamma}{p}\right)^{\frac{1}{1+\rho_{1}}}\right)^{-1}
\end{aligned}
$$

Since this condition holds as long as $p>\gamma>0$, the statement follows.

Lemma 9 The aggregate output $Y$ or $y=\frac{Y}{N_{I I}^{d}}$ grows with the rate of technological progress in steady-state.

Proof: Using 5 we know that $y(t)=\int_{t-m}^{t} y(v, t) d v$. Corollary 4 shows how income of different vintages are related to each other and $y(v, t)=y(0,0) e^{\frac{1}{1+\rho_{4}} \hat{\lambda} t} e^{\frac{\rho_{4}}{1+\rho_{4}} \hat{\lambda} v}$. Plugging in and solving provides

$$
\begin{aligned}
y(t)= & \int_{t-m}^{t} y(0,0) e^{\frac{1}{1+\rho_{4}} \hat{\lambda} t} e^{\frac{\rho_{4}}{1+\rho_{4}} \hat{\lambda} v} d v \\
= & y(0,0) e^{\frac{1}{1+\rho_{4}} \hat{\lambda} t} \frac{\rho_{4}}{\left(1+\rho_{4}\right) \hat{\lambda}} e^{\frac{\rho_{4}}{1+\rho_{4}} \hat{\lambda} t} \\
& -y(0,0) e^{\frac{1}{1+\rho_{4}} \hat{\lambda} t} \frac{\rho_{4}}{\left(1+\rho_{4}\right) \hat{\lambda}} e^{\frac{\rho_{4}}{1+\rho_{4}} \hat{\lambda}(t-m)} \\
= & y(0,0) \frac{\rho_{4}}{\left(1+\rho_{4}\right) \hat{\lambda}} e^{\hat{\lambda} t}\left[1-e^{\frac{\rho_{4}}{1+\rho_{4}} \hat{\lambda}(-m)}\right]
\end{aligned}
$$

Taking the time derivative provides

$$
\begin{aligned}
\dot{y}(t)= & y(0,0) \frac{\rho_{4}}{\left(1+\rho_{4}\right) \hat{\lambda}} \hat{\lambda} e^{\hat{\lambda} t}\left[1-e^{\frac{\rho_{4}}{1+\rho_{4}} \hat{\lambda}(-m)}\right] \\
& +y(0,0) \frac{\rho_{4}}{\left(1+\rho_{4}\right) \hat{\lambda}} e^{\hat{\lambda} t} \frac{\rho_{4}}{1+\rho_{4}} \hat{\lambda} \dot{m}
\end{aligned}
$$

Dividing $\dot{y}(t)$ by $y(t)$ and assuming $\dot{m}(t)=0$ we obtain $\frac{\dot{y}}{y}=\hat{\lambda}$ :

$$
\frac{\dot{y}(t)}{y(t)}=\frac{y(0,0) \frac{\rho_{4}}{\left(1+\rho_{4}\right) \hat{\lambda}} \hat{\lambda} e^{\hat{\lambda} t}\left[1-e^{\frac{\rho_{4}}{1+\rho_{4}} \hat{\lambda}(-m)}\right]}{y(0,0) \frac{\rho_{4}}{\left(1+\rho_{4}\right) \hat{\lambda}} e^{\hat{\lambda} t}\left[1-e^{\frac{\rho_{4}}{1+\rho_{4}} \hat{\lambda}(-m)}\right]}=\hat{\lambda}
$$


Theorem 10 The equations (1) and (18) uniquely determine the human capital intensity $\kappa(0,0)$ and the quasi-rent $r$, which is constant in steady-state, if the following condition holds

$$
\tau_{1}<\tau_{1}^{\max }:=\frac{(1-\alpha) \int_{0}^{m} \frac{N_{I I}^{d}(0, v)}{N_{I I}^{d}(0,0)} e^{\frac{1}{1+\rho_{4}} \hat{\lambda} v} d v}{\left(1-q\left(\tau_{2} Y(t)\right)\right) \int_{-m}^{0} \frac{N_{I I}^{d}(v, 0)}{N_{I I}^{d}(0,0)} e^{\frac{\rho_{4}}{1+\rho_{4}} \hat{\lambda} v} d v}
$$

Proof: In steady-state equation (1) can be written as

$$
\begin{gathered}
\kappa(0,0)=\tau_{1} y(0)=\tau_{1}\left(1-q\left(\tau_{2} Y(t)\right)\right) \int_{-m}^{m} \frac{N_{I I}^{d}(v, 0)}{N_{I I}^{d}(0,0)} y(v, 0) d v \\
\Longleftrightarrow \quad f_{1}(r):=\frac{\kappa(0,0)}{y(0,0)}=\tau_{1}\left(1-q\left(\tau_{2} Y(t)\right)\right) \int_{-m}^{0} \frac{N_{I I}^{d}(v, 0)}{N_{I I}^{d}(0,0)} e^{\frac{\rho_{4}}{1+\rho_{4}} \hat{\lambda} v} d v .
\end{gathered}
$$

It is $\frac{\partial y(0,0)}{\partial \kappa(0,0)}=(1-\alpha) \frac{y(0,0)}{\kappa(0,0)}$ and due to Corollary $4 y(0, v)=y(0,0) e^{\frac{1}{1+\rho_{4}} \hat{\lambda} v}$. Therefore, equation (18) can be written as:

$$
f_{2}(r):=\frac{\kappa(0,0)}{y(0,0)}=(1-\alpha) \int_{0}^{m} \frac{N_{I I}^{d}(0, v)}{N_{I I}^{d}(0,0)} e^{\frac{1}{1+\rho_{4}} \hat{\lambda} v} e^{-r v} d v .
$$

$f_{1}(r)$ is a constant function and $f_{2}(r)$ a monotone increasing function. The uniqueness follows. The existence is fulfilled, if

$$
f_{1}(0)<f_{2}(0) \quad \Longleftrightarrow \quad \tau_{1}<\frac{(1-\alpha) \int_{0}^{m} \frac{N_{I}^{d}(0, v)}{N_{I I}^{d}(0,0)} e^{\frac{1}{1+\rho_{4}} \hat{\lambda} v} d v}{\left(1-q\left(\tau_{2} Y(t)\right)\right) \int_{-m}^{0} \frac{N_{I I}^{d}(v, 0)}{N_{I I}^{d}(0,0)} e^{\frac{\rho_{4}}{1+\rho_{4}} \hat{\lambda} v} d v}=\tau_{1}^{\max }
$$

holds.

Lemma 11 There exist a structure of expenditure on education $R_{I} / R_{I I}$ that maximizes vintage-specific wages $w_{V}(v, t)$ for every employed vintage $v$.

Proof: From the Lagrange problem

$$
\begin{aligned}
\underbrace{L\left(\varepsilon_{I}, \varepsilon_{I I}, \psi\right)=}_{\max \varepsilon_{I}, \varepsilon_{I I}, \psi} & c_{4}\left(\frac{\varepsilon_{I} Y(t)}{N^{s}(t, t)} \frac{\left(1-q\left(\varepsilon_{I I}\right)\right) N^{s}(t, t)}{N_{I I}^{d}(t, t)}\right)^{1-\alpha} \frac{N_{I I}^{d}(t, t)}{\left(1-q\left(\varepsilon_{I I}\right)\right) N^{s}(t, t)} \\
& +\psi\left(\varepsilon_{I}+\varepsilon_{I I}-\varepsilon_{o p t}\right) \\
\text { with } c_{4}:= & =\left[e^{-\frac{\rho_{4}}{1+\rho_{4}} \hat{\lambda} m}\left(1-\left(\frac{\gamma}{p}\right)^{\frac{1}{1+\rho_{1}}}\right)-\alpha\right] c_{1}[\lambda(t, t)]^{\alpha}
\end{aligned}
$$


we obtain as F.O.C.

$$
\begin{aligned}
\frac{\partial L}{\partial \psi} & =\varepsilon_{I}+\varepsilon_{I I}-\varepsilon_{o p t}=0 \\
\frac{\partial L}{\partial \varepsilon_{I}} & =(1-\alpha) c_{4}\left(\frac{\varepsilon_{I} Y(t)}{N^{s}(t, t)} \frac{\left(1-q\left(\varepsilon_{I I}\right)\right) N^{s}(t, t)}{N_{I I}^{d}(t, t)}\right)^{-\alpha} \frac{Y(t)}{N^{s}(t, t)}+\psi=0 \\
\frac{\partial L}{\partial \varepsilon_{I I}} & =\alpha c_{4}\left(\frac{\varepsilon_{I} Y(t)}{N^{s}(t, t)} \frac{\left(1-q\left(\varepsilon_{I I}\right)\right) N^{s}(t, t)}{N_{I I}^{d}(t, t)}\right)^{-\alpha-1}\left(\frac{\varepsilon_{I} Y(t)}{N^{s}(t, t)}\right)^{2} \frac{1}{N_{I I}^{d}(t, t)} \frac{Y(t)}{\lambda(t, t)}+\psi=0 .
\end{aligned}
$$

It can be shown that the implicit function theorem can be applied to determine an optimal solution $R_{I} / R_{I I}$. The solution is a maximum because the matrix of second derivatives is negative definite. 